\title{
Psychological Resilience Interventions to Reduce Recidivism in Young People: A Systematic Review
}

\author{
Rowan Hodgkinson $^{1}\left[\right.$ D Stuart Beattie ${ }^{1} \cdot$ Ross Roberts $^{1} \cdot$ Lew Hardy $^{1}$
}

Received: 30 April 2020 / Accepted: 14 July 2020 / Published online: 24 July 2020

(c) The Author(s) 2020

\begin{abstract}
"Diversion" schemes encouraging children and young people away from offending have successfully reduced the numbers of young people within the youth justice system. However, for those not successfully diverted, recidivism remains obstinately high. Many of those remaining in the youth justice system appear to have complex psychological needs. Research has also shown that many of this group have experienced a high number of adverse childhood experiences. Investigation into the potential consequences of these experiences suggests the potential disruption of normative adolescent psychological growth. Domains may include emotional, cognitive, behavioral, and interpersonal development. This review assesses the effectiveness of individual interventions that had a psychological focus and succeeded in reducing recidivism. A systematic research review from 2000 to 2019 yielded 206 studies for youth offenders, and of these, 14 met the criteria for inclusion. Sample size varied greatly, from 30 to 3038. Research design, follow-up period and intervention content also varied greatly. Further, intervention success for recidivism ranged from almost total desistance to changes (increased time to re-offend) affecting only $50 \%$ of the intervention group. Psychological changes as a result of intervention included an increased sense of coherence, improved emotion recognition, more positive decision-making and reduced defiance. However, none of the studies conducted follow-up psychological assessments post-intervention. Although youth crime is a priority for policy makers, so far research has fallen short of fully examining how the development of psychological resilience via interventions may help reduce persistent offending.
\end{abstract}

Keywords Resilience · Psychological interventions · Recidivism · Re-offending · Juvenile · Youth · Delinquency · Systematic review

\section{Introduction}

Due to the overall success of youth justice diversion schemes such as counselling and victim awareness, the pool of young people within the youth justice system is no longer "watered

This research is part of a Knowledge Economy Skills Scholarships (KESS 2) funded research project, project code: C80815. KESS

2 is a major pan-Wales operation supported by European Social Funds (ESF) through the Welsh Government. KESS 2 links companies and organisations with academic expertise in the Higher Education sector in Wales to undertake collaborative research projects, working towards a PhD or Research Masters qualification. The collaborating company on this project is the Youth Justice Service for Gwynedd and Ynys Môn to which none of the authors have any affiliation or financial connections.

Rowan Hodgkinson

pepa35@bangor.ac.uk

Extended author information available on the last page of the article down" by less serious or "adolescent-limited" youth offenders (Moffitt 2003). This phenomenon has highlighted the complex needs of those individuals who remain in the youth justice system, many of whom become repeat offenders. Research shows that this population experience high levels of trauma, difficulties understanding emotional states, substance misuse, and mental health issues (Mallet and Tedor 2018). Re-offending rates are high, suggesting a distinct need for focused research attention on this worldwide concern. However, despite the notable psychological difficulties experienced by those who re-offend, there has not been a systematic review of psychological interventions that have succeeded in reducing re-offending. This study, therefore, aims to address that research gap by identifying successful interventions world-wide and reporting on the psychological changes occurring along with reduced re-offending. 


\section{Definition of "Young Offender"}

A "young offender" is a child or a youth convicted or cautioned by the police. The age of criminal responsibility varies between countries. In Europe and Asia, it is 12-14. In the UK, Ireland and Australia it is 10. However, in the USA, 33 out of the 50 states set no minimum age but instead apply a capacity test. Of the 17 that do, North Carolina has the lowest at 7, and Wisconsin has the highest at 10. In Scandinavian countries which include Denmark, Finland, Norway, and Sweden, the legal age of criminal responsibility is 15 . In most countries, youth justice services can work with individuals until they turn 18 (although the United Nations class a "youth" as between the ages of 15 and 24, Factsheet on Juvenile Justice 2008). In the UK, a "prolific young offender" is an individual aged between 10 and 17 who has more than 25 separate offences (Johns et al. 2018).

Global Youth Justice report that that over the last 5 years, the most common reasons for convictions/cautions of children and youth worldwide consisted of theft, vandalism, underage drinking, disorderly conduct (e.g., fighting or assault), marijuana possession, underage smoking, curfew violation, school disciplinaries and traffic violations (e.g., underage driving) (Top 25 crimes, offences and violation 2018). While youth diversion schemes are effective at ensuring a high number of children and youth do not go on to commit further or more serious crime, they are not always successful (Wilson and Hoge 2013). For example, a 2015 report from the U.S.A. compiled data from the 39 states that track recidivism found that $76 \%$ of first-time offenders re-offended within 3 years, and $84 \%$ within 5 years (MST Services 2018). In the U.K., re-offending rates are similar, especially for youth leaving secure institutions where over two thirds reoffend within 12 months of release (Youth justice facts and figures 2020).

"Serious" crimes committed by children and youth are often associated with gang involvement, e.g. knife crime or violent crime (Association of Directors of Children's Services 2019). "Less serious" offenders are those that have committed offences considered to be non-violent in nature such as property crimes (Turner 2015). Those who commit serious crimes are less likely to receive diversion options such as restorative justice schemes. There are many crimes other than violent listed as "serious" in various legislations worldwide but these are more likely to be committed by adults, e.g. drug trafficking, people and arms trafficking, prostitution and child sex offences, armed robbery, bribery, computer misuse offences and environment offences (Serious Crime Act 2007).

\section{Psychological Development}

Adolescence is a crucial period when cognitive and emotional skills develop for successful transition into adulthood (Wood et al. 2018). However, research has shown that children and youth in the criminal justice system are more likely to experience delayed cognitive development, evidenced by factors such as poor emotional regulation and low academic attainment (Wolff and Baglivio 2017). Consequently, this may lead to low levels of psychological resilience, e.g. inability to successfully overcome difficulties. Further, measures of re-offending and resilience do not always go hand in hand, meaning the relationship between psychological development/resilience and reduced offending is unclear (cf. Daykin et al. 2017).

One cause of delayed cognitive development in young people is the experience of trauma. For example, studies report that these individuals often have difficulties in recognizing emotions in others, or in identifying and describing their feelings (alexithymia) in themselves (Möller et al. 2014). An inability to recognize emotions may be one of the ways in which traumatic experiences impede normative psychological development (Eichhorn et al. 2014). Delayed cognitive development such as language impairment has also been specifically related to children and youth who offend (Snow et al. 2015). Overall, research finds that experiencing trauma at a young age often leads to higher levels of negative emotionality such as anger, greater levels of anxiety and depression, and low levels of relatedness and self-concept (Gibson and Clarbour 2017).

Psychological trauma can result from adverse childhood experiences such as loss of a parent or experiencing violent events, as well as responses to chronic or repetitive experiences such as child abuse, neglect, urban violence, violent relationships, and chronic deprivation (Committee on Child Maltreatment Research, Policy, and Practice for the Next Decade 2014). Sudden changes such as loss or bereavement may also include having to leave the family home due to conflict, abuse, or overcrowding (Diaz 2005). Incarceration also signifies sudden loss of the familiar, a potentially traumatic experience related to separation pain (Armstrong and Weaver 2013). Research has also shown that the combination of trauma previously experienced by many of those incarcerated with further deprivation experienced as part of the prison environment, can lead to further traumatization (Armour 2012). Therefore, incarceration for youth who may already lack resilience may further delay psychological growth, hindering normative adolescent development and potentially contributing to difficulties transitioning to adulthood.

General strain theory may help explain why negative childhood experiences lead to offending behavior in some 
individuals (Agnew 2001). This predicts that delinquent behavior occurs when there are disconnections between common goals and the availability of legitimate ways of reaching those goals. Goals may include desire for material items or need for status. For example, deviant subcultures may arise from the need for social recognition (Barry 2006). Gang membership provides an achievable means of meeting this need (U. S. Department of Justice 2015). One study examined the effect of eight strain factors on delinquency including both general and specific factors. Results showed negative relationships with adults and parental fighting combined with other negative life events and life hassles were significantly associated with delinquency (Agnew and White 1992). Other studies suggest youth who have experienced childhood adversity are more likely to experience frustration or difficulties dealing with emotions (i.e., negative emotionality) which often manifests into aggressive behavior (Wolff and Baglivio 2017). In other words, without necessary skills to manage emotions or achieve goals/basic needs via conventional channels, youth may utilize unhelpful methods to meet these needs such as through violence and/or gang membership.

\section{Development of Psychological Resilience}

However, not all children and youth who experience significant childhood trauma will go on to engage in anti-social behavior. Research suggests that the concept of psychological resilience and its development during adolescence, may serve as a protective factor in those who experience trauma that do not offend (Agaibi and Wilson 2005). The concept of psychological resilience followed in this review comes from a theoretical model incorporating stress, emotions, and behavior whereby processes of belief, appraisal, and coping mediate the stress responses arising from the individual's environment. This in turn can lead to positive or negative responses, feeling states, and outcomes (Fletcher and Scott 2010). A chronically negative response such as anger or aggression may indicate low psychological resilience. Positive emotional states can also act as a moderating attribute, influencing the extent to which trauma affects behavior (Infurna et al. 2015).

Within the literature, researchers often define resilience as the interplay between risk and protective factors (e.g., Stoddard et al. 2013). Although many definitions of resilience exist (e.g., Luthar et al. 2000), perhaps most pertinent to children and youth who offend is that those deemed resilient have "good psychological functioning and good behavioral outcomes despite adverse circumstances expected to jeopardize normative growth and adaptation" (Mukherjee and Kumar 2017, p. 3). Findings from resilience research acknowledge that resistance to adversity may derive from a range of physiological or psychological coping processes rather than external protective factors (Rutter 2006). That is, the extent to which youth develop psychologically during the critical period of adolescence, may be paramount to how well they are able to create and take advantage of protective factors in times of adversity (Steinberg et al. 2004). Given the complex psychological profiles of children and youth who offend, understanding the effectiveness of psychological interventions aimed at reducing offending in this population is paramount. While studies increasingly find that individuals can develop these resources at any stage in life, research generally finds antisocial individuals tend to have a better response to intervention in early developmental stages such as adolescence (Salekin 2015).

\section{Current Study}

Several researchers have conducted reviews on the efficacy of various interventions for children and youth engaging in delinquent behavior. For example, studies show that factors determining intervention success included intervention type, methodological rigor, intervention design, demographics, extent of supervision and intervention philosophy (Lipsey 2009). Other research finds psychosocial interventions that reduced aggressive and violent offending were effective providing they contained elements of emotional selfmanagement and focused on increasing interpersonal and social problem-solving skills (McGuire 2008). However, McGuire (2008) stopped short of outlining exactly how these variables related to reduced offending. Therefore, despite research evidence indicating that effective psychological interventions reduce delinquent behavior and that psychological resilience may offer protection from the adverse effects of trauma, there is a need to systematically review this evidence to better inform researchers and practitioners of best practice.

\section{Method}

\section{Search Strategy}

This review followed guidelines from the Preferred Reporting Items for Systematic Reviews and Meta-analyses Statement (PRISMA, Moher et al. 2009) which enabled systematic selection of studies for this review. In July 2019, databases searched consisted of Psycinfo and ASSIA (via the Proquest platform), PubMedCentral, Wiley, Taylor and Francis, JSTOR, Cochrane Central, Sage and PsycNet (APA). These databases allowed full text searches, enabling identification of articles omitting key words in their titles and abstracts. The first author initially read and checked all titles and abstracts against the eligibility and exclusion criteria 
listed below. Focusing on psychological interventions for repeat offenders that had reduced offending and included psychological measures, searches included studies published between 2000 and 2019 and written in the English language.

Initial specific search terms identified empirical research on psychological interventions for children and youth who offend, and further search terms emerged during the iterative searching process. The search terms are listed as follows: (adolescen* OR youth OR young OR teen* OR juvenile OR offend* OR persistent OR conduct OR delinquen* OR problem) AND (intervention OR program* OR treat* OR measure OR outcome OR evaluation) AND (resilien* OR protective OR cognitive OR self-regulation OR self-efficacy OR strengths) AND (individual OR self OR behav* OR psychological) AND (recidiv* OR desist* OR justice OR re-offend*). Full-text database searches were key to identifying relevant articles as this enabled the inclusion of articles where key words did not appear in the title or the abstract.

The first author followed up the database searches with backwards and forwards reference searches to identify further relevant articles. The backwards searches involved scanning reference lists for further eligible studies, and the forwards searches used the "cited by" function provided by the database used. Documents searched consisted of reviews, systematic reviews and meta-analyses identified during the database searches, as well as the intervention studies selected for the review. In addition, the authors conducted searches in several key organizations' websites (Youth Justice Board, Home Office).

\section{Inclusion and Exclusion Criteria}

The current review included evaluations of: (a) psychological interventions for children and youth who offend or systematic interventions that included measures of psychological change or targeted specific psychological variables; (b) journals written in the English language; (c) children and youth who have offended more than once or are experiencing a disproportionately high risk for doing; (d) interventions that included a control group; (e) interventions that demonstrated a reduction in the amount of offending, time between offending episodes, or a reduction in the seriousness of offending; (f) papers published from the year 2000. The reason for this selection was that interventions after the year 2000 had to meet the first set of National Standards specific to the Youth Justice Board for England and Wales (a government body introduced under the Crime and Disorder Act (1998) to oversee the youth justice system). Its overall aim is to prevent children and youth from offending or re-offending, to ensure custody is safe and secure, and to address underlying causes of offending behavior (Youth Justice Board 2018). Studies excluded were those which were systemic in nature (i.e., targeted many areas of the individual's life) and did not utilize psychological measures, as it would not be possible to surmise what psychological changes occurred along with reduced offending. Other studies excluded were those for sex offenders due to the specific nature of this offence and the large number of interventions for this population suggests a separate review.

Following examination of the effect of attrition rate (i.e., individuals not completing a program) and in line with Evans-Chase and Zhou 2014), the authors decided to exclude studies with attrition of $40 \%$ or higher. This is because attrition rates may bias outcome evaluations as participants may have lacked motivation to engage with interventions, reducing their success (Hatcher et al. 2012). Figure 1 shows the PRISMA flow chart detailing the review and selection process.

\section{Assessment of Study Quality}

There were notable variations in group sizes, intensity, follow-up periods, and reported outcomes. Therefore, a meta-analysis was not possible. Instead, the 16-item quality assessment tool assessed overall study quality in studies meeting eligibility and inclusion criteria (QATSDD; Sirriyeh et al. 2012). The QATSDD contains a list of criteria for quantitative and qualitative studies rated on a 4-point scale, ranging from 0 (not at all) to 3 (complete). Relevant criteria's i.e. those applying to quantitative, qualitative, or mixed method designs included "Clear description of research setting"; "Detailed recruitment data"; "Strengths and limitations critically discussed". Division of the total score for each study by the maximum possible score resulted in a percentage for standardization purposes. The first three authors assessed study quality. Specifically, each author scored ten research studies (i.e., two authors assessed each study). Subsequent discussions resolved any disagreements. Table 1 presents all studies reviewed along with quality scores.

\section{Reliability}

Following the screening of titles in 12 database searches conducted by the first author, the second author re-screened 6 randomly selected database searches (totaling 4279 titles) to assess interrater reliability. This process did not identify any additional titles. The first author next read the abstracts of all titles identified and selected 181 for full-text analysis. The first author then selected 99 titles for full-text analysis. To ensure agreement on the decision-making process, the second author read 40 randomly selected article abstracts from the 181 selected and specified which articles they would select for full-text analysis. Subsequent discussions resolved any disagreements. Finally, the first and second authors read all 99 articles, to reach full agreement on which studies to include in the review based on the inclusion and 
Fig. 1 PRISMA flow chart
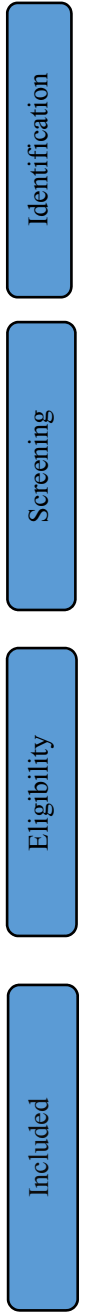

Additional records identified through other sources $(n=25)$ searching $(\mathrm{n}=47,537)$

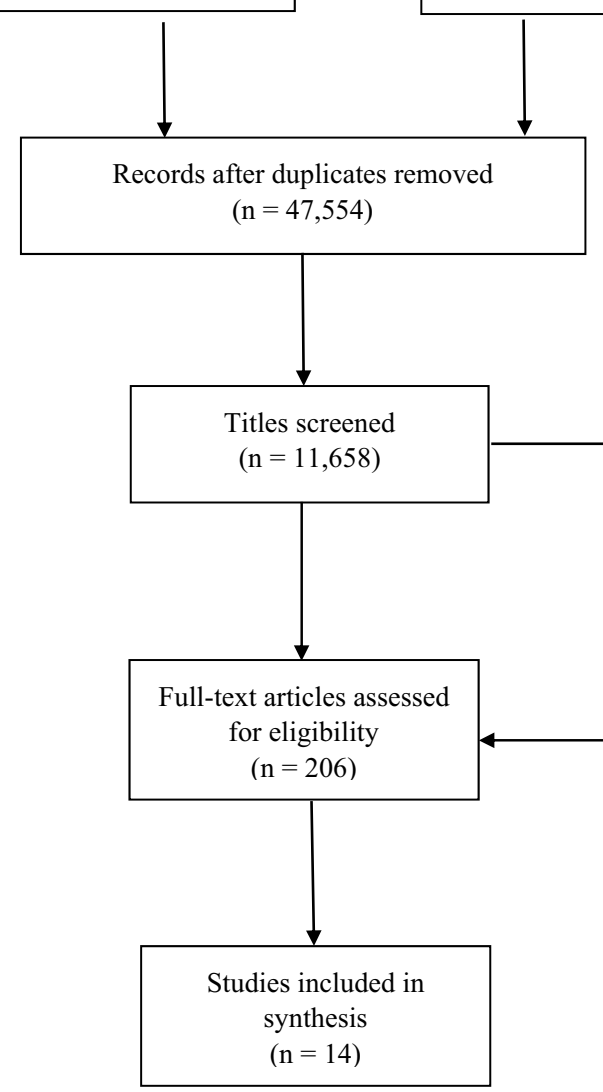

Records excluded $(\mathrm{n}=11,452)$

Full-text articles excluded $(n=192)$

Re-offending not measured -51 For adults- 31 No control -27 Family intervention -13 $1^{\text {st }}$ time / at risk -14 Non-significant -13

Whole school - 7 Study protocol only -6 Dropouts as control - 5 Systemic/no psych measures -5 Insufficient detail - 5 Description only - 3 Not an intervention -2 Comparison of two interventions - 4 Did not control for group differences -2

Review - 2

Follow-up study - 1 Iatrogenic - 1

exclusion criteria reported above. This agreement consisted of verifying through discussion whether the article fully met all criteria.

\section{Results}

The database search in July 2019 identified 47,537 records. Reference and citation searches identified a further 25 records. After removing eight duplicates and screening a total of 11,658 titles, the first author read 206 abstracts. Full text was next assessed in 99 research studies by both first and second authors. Subsequently, fourteen interventions met the inclusion criteria. These fourteen studies report on twelve different interventions (four studies assessed the same intervention twice with different sample; Bahr et al. 2015; Burraston et al. 2014; Caldwell and Rybroek 2001; Caldwell et al. 2006). The 14 studies included in the review have an asterisk in the bibliography.

\section{Study Design}

A total of thirteen studies used quantitative approaches and one used mixed methods (Burraston et al. 2014). With 


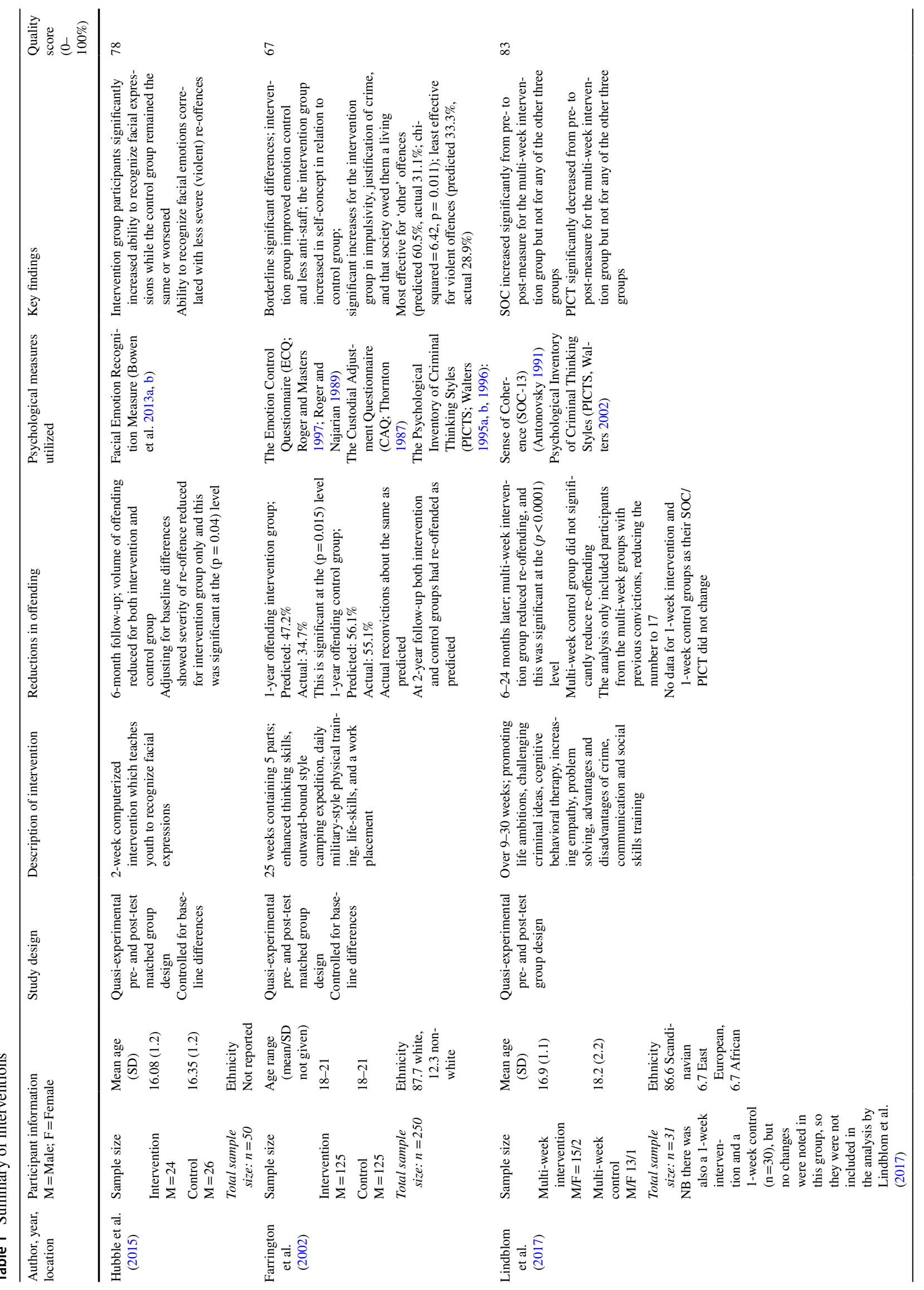




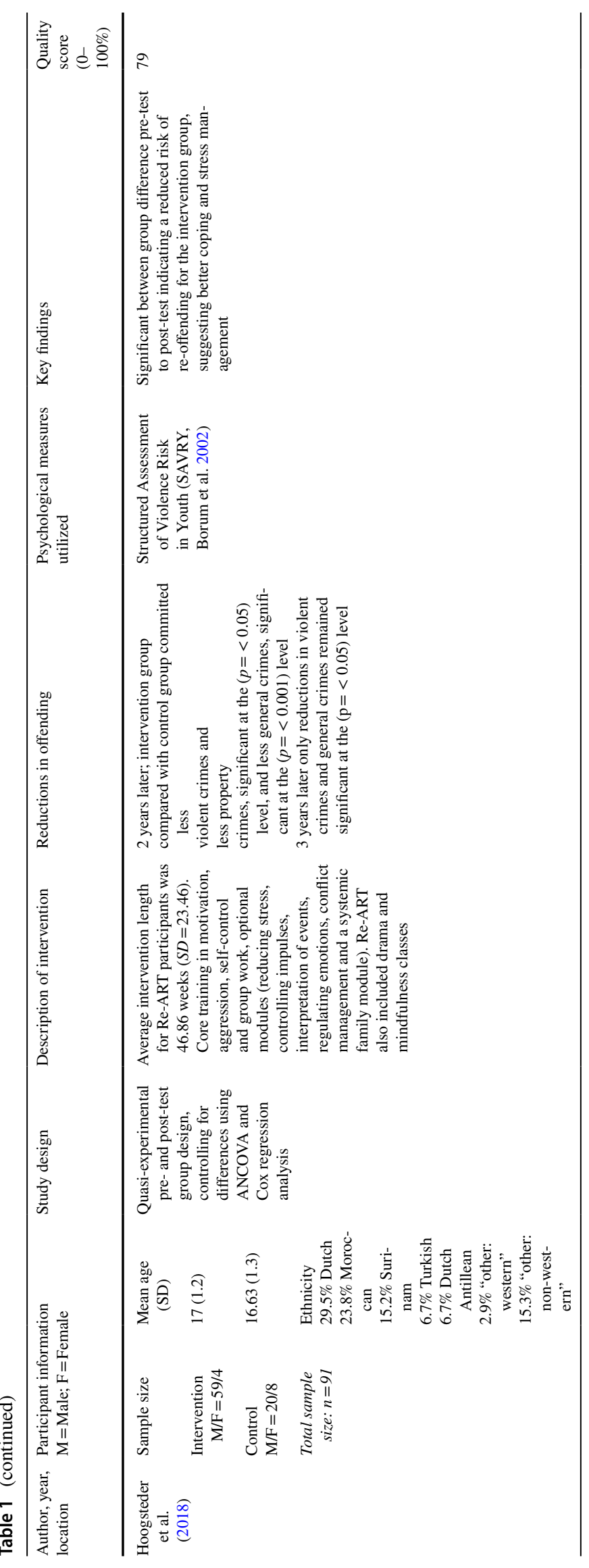




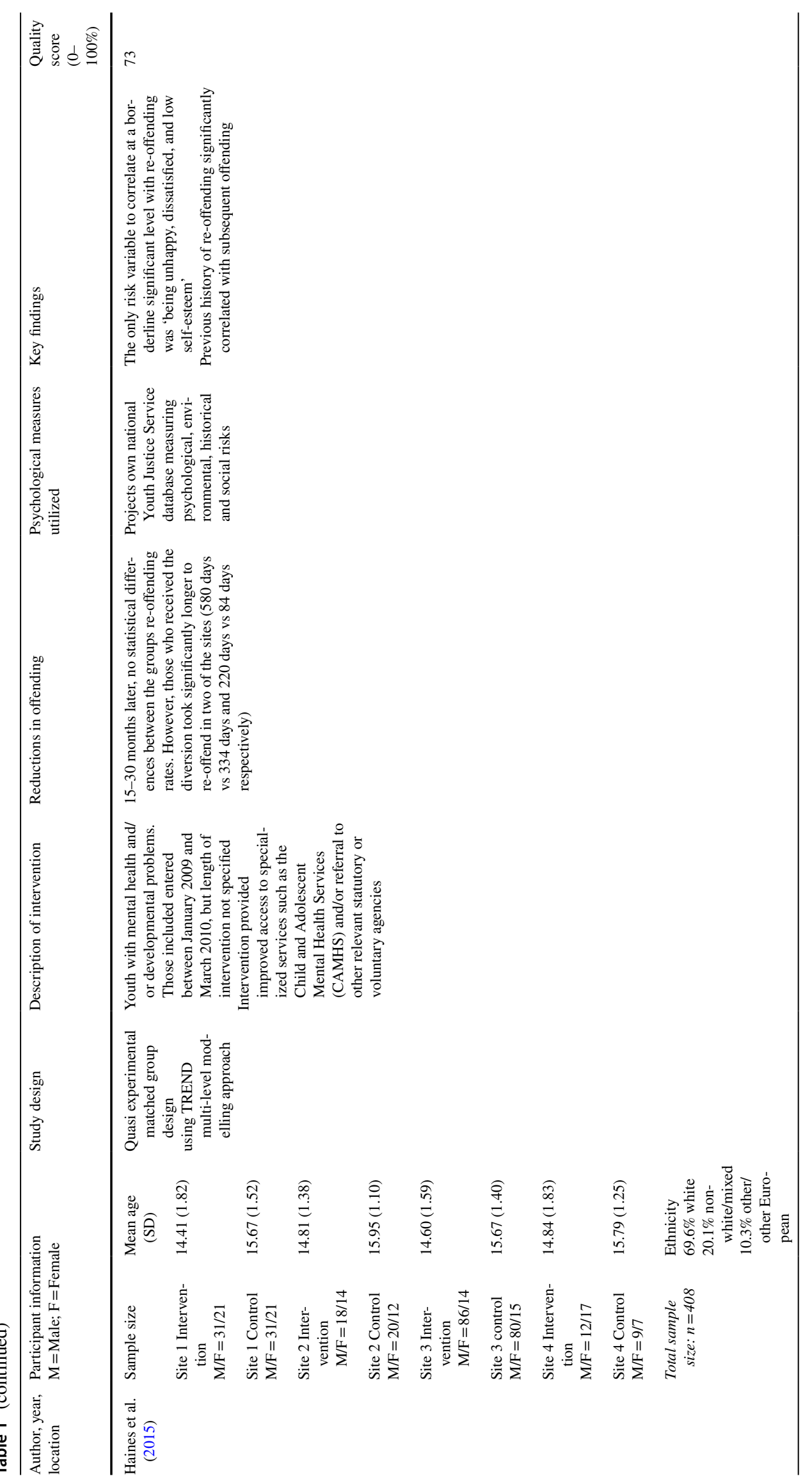




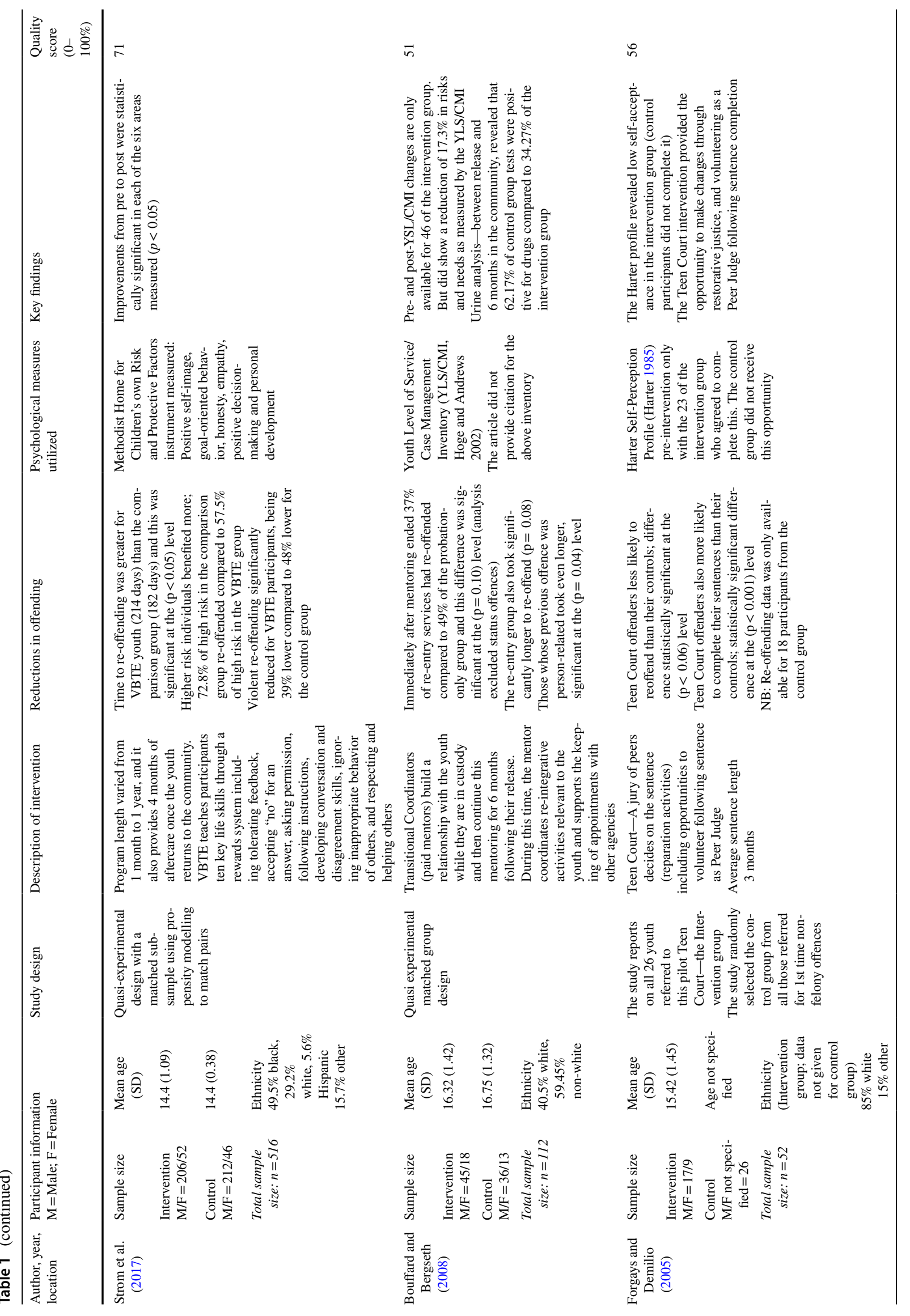




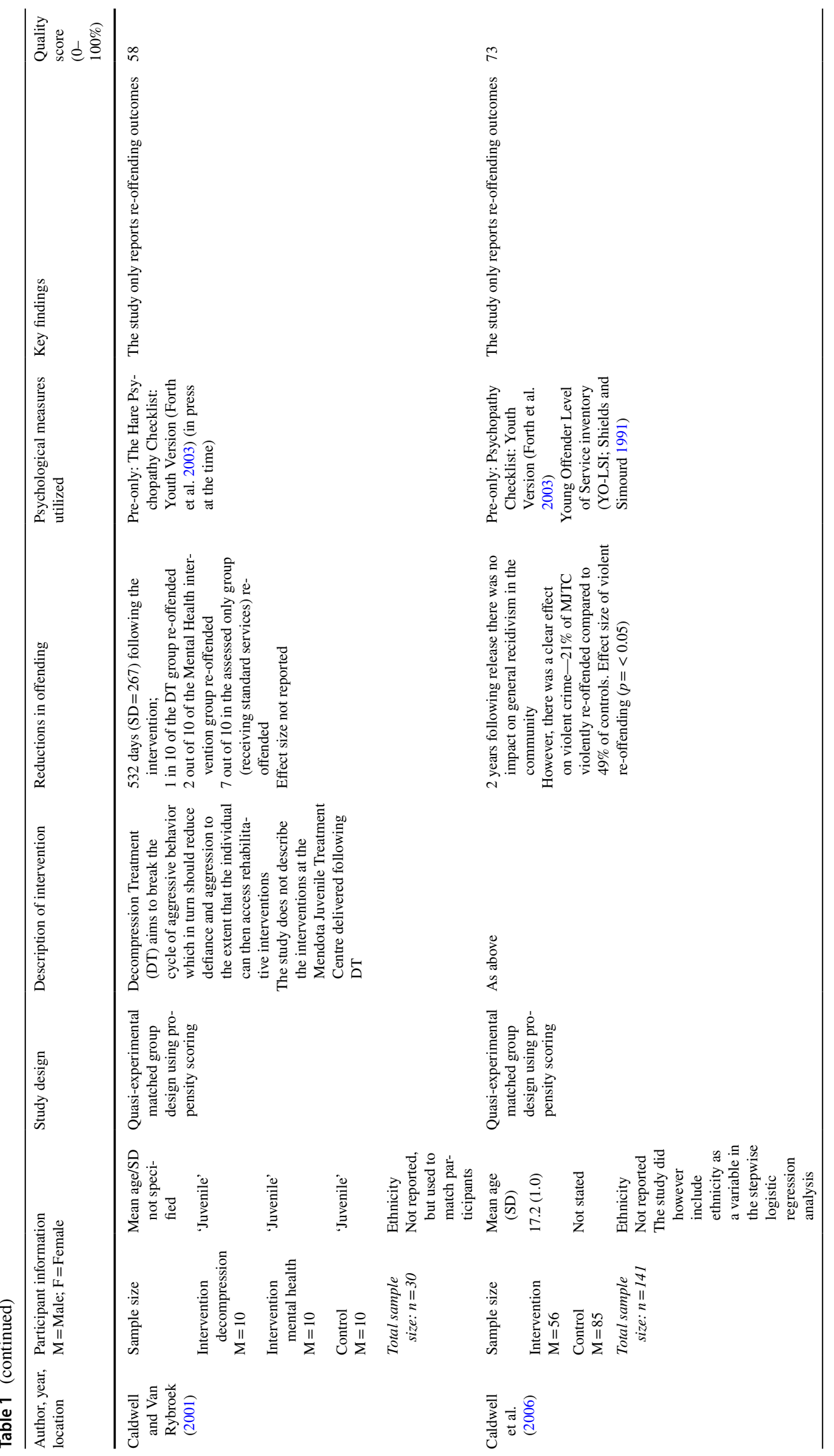




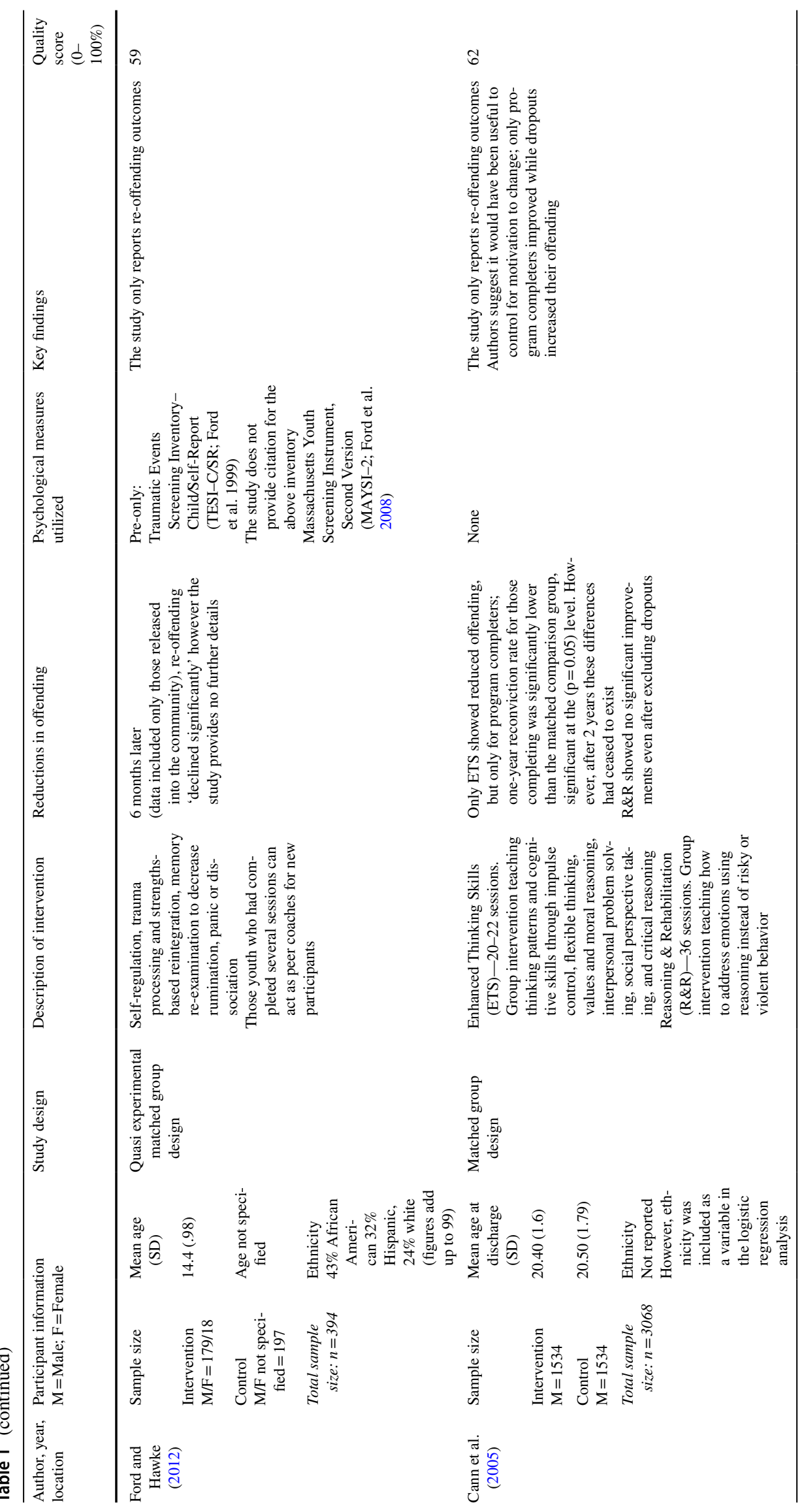




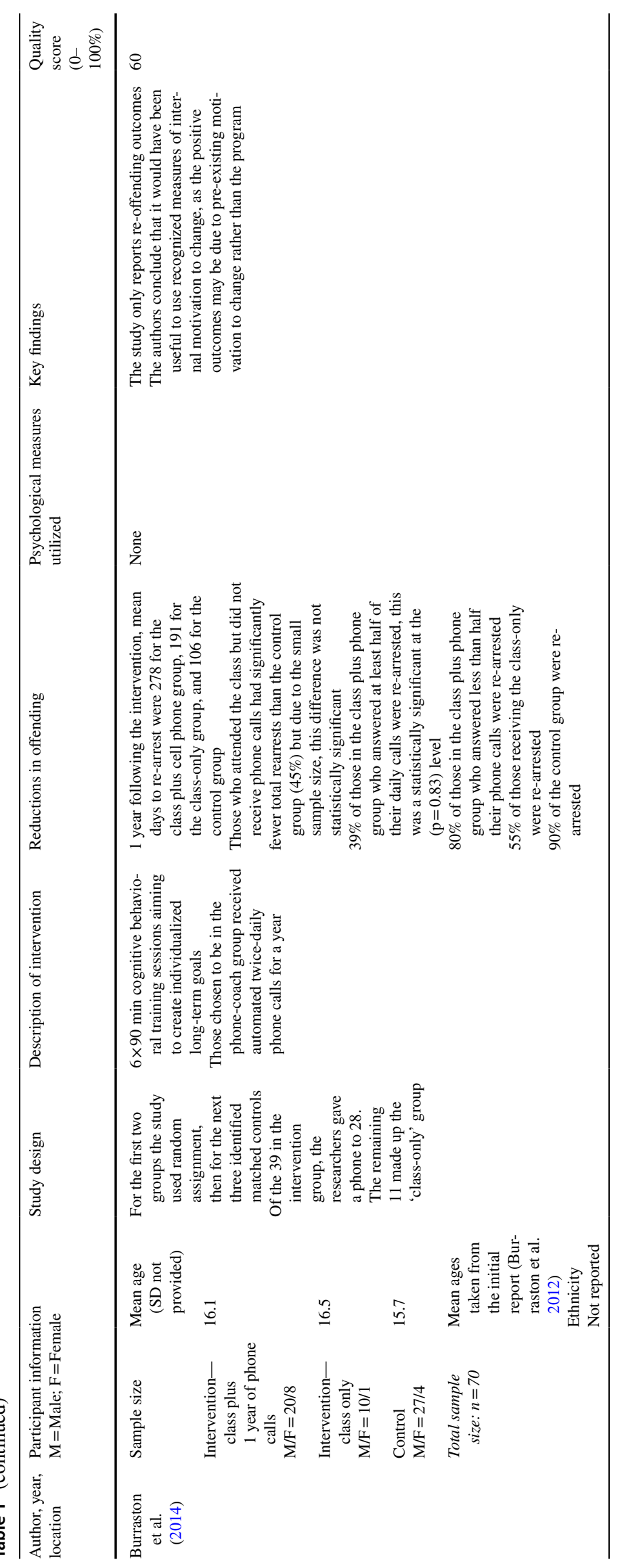




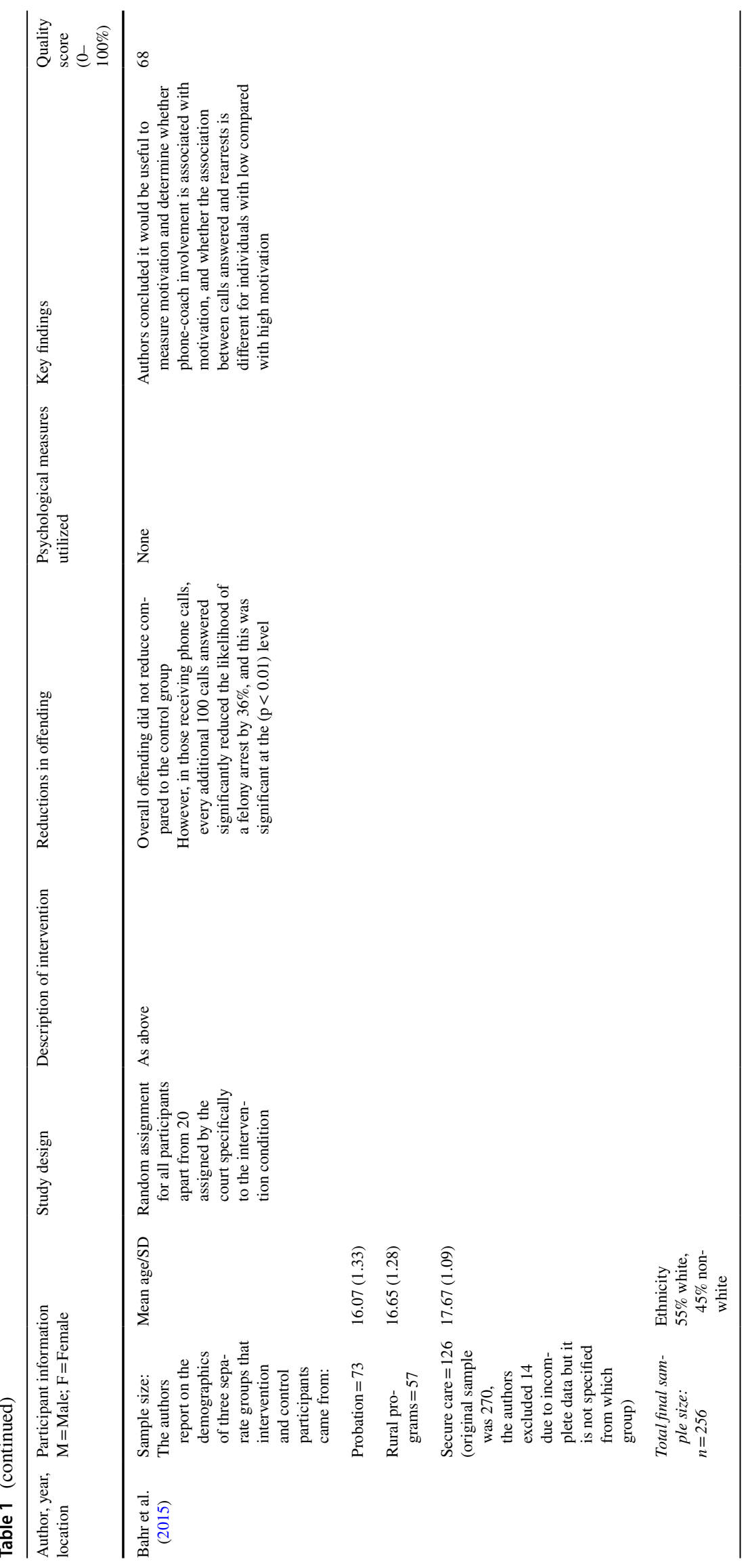


regards to control group selection, twelve studies used a matched control, one used random allocation (Bahr et al. 2015) and one randomly selected the control group (Forgays and DeMilio 2005). However only six of those studies using matched controls controlled for baseline differences (Caldwell and Rybroek 2001; Caldwell et al. 2006; Farrington et al. 2002; Haines et al. 2015; Hoogsteder et al. 2018; Strom et al. 2017).

\section{Settings}

Of the studies identified, five were based in the community (Bouffard and Bergseth 2008; Burraston et al. 2014; Forgays and DeMilio 2005; Haines et al. 2015; Hubble et al. 2015). However, one of those studies contained youth nearing the end of their custodial sentence before continuing in the community (Bouffard and Bergseth 2008). Participants in seven of the studies resided in custodial placements. That is, three studies used participants from standard "young offender institutions" (Cann et al. 2005; Farrington et al. 2002; Hoogsteder et al. 2018), one examined participants from placements described as "residential homes" (Strom et al. 2017), and three consisted of therapeutic custodial placements (Caldwell and Rybroek 2001; Caldwell et al. 2006; Ford and Hawke 2012). The two remaining studies recruited youth from both the community and custodial placements (Bahr et al. 2015; Lindblom et al. 2017).

\section{Country of Origin}

Of the interventions, eight originated from the USA (Bahr et al. 2015; Bouffard and Bergseth 2008; Burraston et al. 2014; Caldwell and Rybroek 2001; Caldwell et al. 2006; Ford and Hawke 2012; Forgays and DeMilio 2005; Strom et al. 2017), four from the UK (Cann et al. 2005; Farrington et al. 2002; Haines et al. 2015; Hubble et al. 2015), one from the Netherlands (Hoogsteder et al. 2018), and one originated from Sweden (Lindblom et al. 2017).

\section{Population}

The number of intervention participants totaled 2837, and the number of control participants totaled 2715 making a total of 5552. Of those detailing gender, five of the studies contained male participants only totaling 3582 (Caldwell and Rybroek 2001; Caldwell et al. 2006; Cann et al. 2005; Farrington et al. 2002; Hubble et al. 2015) and nine included both genders of which 1587 were male and 337 female (Bahr et al. 2015; Bouffard and Bergseth 2008; Burraston et al. 2014; Ford and Hawke 2012; Forgays and DeMilio 2005; Haines et al. 2015; Hoogsteder et al. 2018; Lindblom et al. 2017; Strom et al. 2017). Across all reported studies, there were 5169 male participants and 337 females. Missing data regarding gender totaled 36 participants. One study was not able to specify the gender of 10 participants (Haines et al. 2015). One study did not report control group gender (Forgays and DeMilio 2005).

Across all studies, age ranged from 14 to 21 years old. In the eight studies that reported age of both intervention and control groups, the average age of the intervention group was 16.17 and the average age of the control group was 16.72 . Finally, one study did not report age at all, simply stating they were "juvenile" (Ford et al. 2008).

With regards to offending histories, eleven participant groups met the criteria for persistent or repeat offenders meaning they had offended at least once previously (but usually more than once). Participants from one group were in the "early stages" of delinquency (Lindblom et al. 2017). One intervention did not include details of previous convictions but did take place in a young offender institution suggesting the youth were either serious offenders, or had offended more than once (Cann et al. 2005). One intervention described the offences as "relatively minor but leading to a reprimand or final warning from the police" (Haines et al. 2015, p. 127). Participation appeared to be voluntary for seven of the intervention groups (Bahr et al. 2015; Burraston et al. 2014; Cann et al. 2005; Farrington et al. 2002; Ford and Hawke 2012; Haines et al. 2015; Lindblom et al. 2017). For five, it appeared to be compulsory (Caldwell and Rybroek 2001; Caldwell et al. 2006; Forgays and DeMilio 2005; Hoogsteder et al. 2018; Strom et al. 2017). It is unclear whether the intervention was voluntary or compulsory for the remaining two groups (Bouffard and Bergseth 2008; Hubble et al. 2015).

\section{Race}

One study reported that $86.6 \%$ were Scandinavian, $6.7 \%$ were East European and $6.7 \%$ were African (Lindblom et al. 2017). Another study reported that $29.5 \%$ were Dutch, 23.8\% were Moroccan, $15.2 \%$ were Surinam, $6.7 \%$ were Turkish, 6.7\% were Dutch Antillean, 2.9\% "other: western" and 15.3\% "other: nonwestern" (Hoogsteder et al. 2018). Of the 8 studies conducted in the U.S.A., 5 report race. That is, one recorded their sample as being $49.5 \%$ black, 29.2\% white, 5.6\% Hispanic and $15.7 \%$ "other" (Strom et al. 2017). One study noted that their sample contained $43 \%$ African American, 32\% Hispanic and 24\% white (Ford and Hawke 2012). Other studies contain less detail; one stated that participants were 55\% white and $45 \%$ non-white (Bahr et al. 2015). Another study reported race as $40.5 \%$ white and 59.45\% non-white (Bouffard and Bergseth 2008). Finally, one study recorded the race of their intervention group as 85\% white and 15\% "other" (Forgays and DeMilio 2005). Although they used race to match intervention and control groups, three studies did not include this data in their 
articles (Burraston et al. 2014; Caldwell and Rybroek 2001; Caldwell et al. 2006). Of the four studies from the U.K, two include race data. One study recorded participants race as $87.7 \%$ white and $12.3 \%$ non-white (Farrington et al. 2002). The second study recorded participants as $69.6 \%$ white, $20.1 \%$ non-white/"mixed" and $10.3 \%$ as "other/other European" (Haines et al. 2015). Although it used race data as a variable for regression analyses, one study did not report participants race, or whether this affected intervention outcomes (Cann et al. 2005). Finally, one study did not specify race in relation to either participant matching or intervention outcomes (Hubble et al. 2015). Overall, in the USA, studies reported $46 \%$ participants as white and $53.06 \%$ as non-white, while in the U.K. these figures were $78.65 \%$ and $21.35 \%$ respectively. However, the U.K. figures do not necessarily give a true picture as overall in the UK, $40 \%$ of young people in custody are from black, Asian and minority ethnic (BAME) backgrounds (Ministry of Justice 2016).

\section{Pre- and Post-psychological Measures}

Five of the research studies identified reported pre- and postpsychological assessment for both intervention and control groups (Farrington et al. 2002; Haines et al. 2015; Hoogsteder et al. 2018; Hubble et al. 2015; Lindblom et al. 2017). A further two studies reported pre- and post-psychological assessment for the intervention groups only (Bouffard and Bergseth 2008; Strom et al. 2017). A further four studies reported pre-intervention psychological assessment but not post-assessment (Caldwell and Rybroek 2001; Caldwell et al. 2006; Ford and Hawke 2012; Forgays and DeMilio 2005). The remaining three studies did not include any measures other than re-offending, but nevertheless targeted predominantly psychological factors in the intervention. As these studies showed a reduction in re-offending and focused specifically on cognitive and emotional well-being, these studies met the criteria for inclusion (Bahr et al. 2015; Burraston et al. 2014; Cann et al. 2005).

\section{Attrition}

Seven studies reported on participant dropout (Bahr et al. 2015; Burraston et al. 2014; Caldwell and Rybroek 2001; Cann et al. 2005; Farrington et al. 2002; Forgays and DeMilio 2005; Hubble et al. 2015). One study reported that 14 participants began but did not complete the study, either because they moved out of state of decided not to continue (excluded from the final analysis) (Bahr et al. 2015). Another study reported that just 2 control and 4 intervention participants dropped out from their study (i.e., moved away from the area) leaving a final sample of 70 (Burraston et al. 2014). One study reported that no participants left the intervention group (Caldwell et al. 2006). Another reported that
$14 \%$ (220) of program starters dropped out (subsequently excluded from the analysis) (Cann et al. 2005). One study reported that out of the 176 who started the program, $71 \mathrm{did}$ not complete (Farrington et al. 2002). Although this gives an attrition rate of $40.34 \%$, the decision to include this study relates to its valuable psychological pre- and post-measures. Another study reported that 26 out of the 27 repeat offenders appeared for their Teen Court sentence and their final analysis consisted of $24(81 \%)$ participants who completed their sentences (Forgays and DeMilio 2005). The final study to report attrition stated that no participants dropped out (Hubble et al. 2015).

\section{Intervention Type and Efficacy}

The types of intervention employed largely addressed areas such as cognitive abilities, mentoring and to a lesser extent, restorative justice. Interventions therefore varied greatly in content, sample size, location and measurement of efficacy. To examine the effectiveness of the interventions reported, the results section below first discusses studies that utilize psychological assessments pre- and post-intervention, followed by those using pre-assessment only. Finally, the results section discusses interventions using no pre- or postassessments. Although it may appear that reporting on such studies may be counter-intuitive, they do fall under the category of studies which show promise.

\section{Studies Reporting Pre- and Post-psychological Measures on Both Intervention and Control Groups}

One intervention consisted of using a facial emotion recognition tool in the form of computerized slides to assess emotional recognition in others (Hubble et al. 2015). At pretest, results revealed both groups (intervention and control) were poor at recognizing fear, sadness and anger in others. A 2-week course then trained participants to recognize facial expressions. At post-test, the intervention group significantly improved their ability to recognize facial expressions of fear, anger and sadness, while their controls either remained the same (in relation to fear and anger) or worsened (in relation to sadness). Results showed the volume of re-offending in both groups significantly decreased 6-months post-intervention. However, offences committed by the intervention group decreased significantly in severity.

Another study to utilize a pre- and post-measure design tested the efficacy of a 25-week High Intensity Training (HIT) intervention (Farrington et al. 2002). In addition to daily military-style training, this intervention also consisted of Enhanced Thinking Skills in conjunction with a 1-week outward-bound style camping expedition that culminated in a work placement. Outward bound interventions may help youth who have experienced difficulties by providing an 
environment that contains a sense of stability which fosters positive interactions between staff and youth (Trundle and Hutchinson 2020).

The assessments conducted on both intervention and control groups included emotion control, adaptation (assessing how well both groups adjusted to incarceration), and criminal thinking styles. Results revealed that the intervention group reported better control of aggression and being less anti-staff (indicating greater levels of adaptation) than the control group. In concert, these findings suggested a more positive adjustment to the custodial and the HIT regime for the intervention group. The authors also noted that there were increases for the intervention group in impulsivity, justification of crime, and belief society owed them a living. These changes were significant at $(p=0.085)$ and $(p=0.008)$ respectively. Even so, following the HIT regime, predicted re-offending compared with actual re-convictions showed that re-convictions were significantly lower for the intervention group compared to the control group 12 months later. There were no differences in offending outcomes for violent/ non-violent offenders. However, 24-months post-intervention these differences were no longer statistically significant in either group (i.e., both groups re-offended as predicted) (Farrington et al. 2002).

The third study to use a pre- and post-measures matched group design tested the efficacy of "A New Direction" (Lindblom et al. 2017). Psychological aspects of this intervention included promoting life ambitions, challenging criminal ideas, cognitive behavioral therapy, increasing empathy (effects on the victims of crime) and problem solving. In addition, it addressed advantages and disadvantages of crime, communication with family and friends, and general social skills training over 9-30 weeks. In order to assess psychological changes, the authors examined Sense of Coherence, which assesses whether life makes sense, is manageable, and has meaning (Eriksson 2016). The authors also assessed criminal thinking styles (Walters 2002). Compared to their controls, the intervention group experienced significant reductions in criminal thinking and a significant increase in Sense of Coherence. The authors report no significant changes in the control group. Twelve months later, the intervention group continued to show sustained desistance in that just one out of the eleven participants had reoffended. By 24 months, out of the 8 in the intervention group for whom data were available, none had re-offended. In the control group, during the 12 months following the intervention, 50\% had re-offended and at a higher rate (Lindblom et al. 2017).

A study evaluating an intervention called Responsive Aggression Regulation Therapy (Re-ART) which specifically targets aggressive behavior, included pre and postmeasures of violence risk to assess its efficacy (Hoogsteder et al. 2018). Participants received core training in areas such as motivation, aggression, self-control and group work, plus optional modules which they could choose from (reducing stress, controlling impulses, re-interpretation of events, regulating emotions, conflict management and a systemic family module). The intervention also included a focus on drama and mindfulness classes. Pre- and post-measures revealed significant reductions in risk, suggesting more pro-social coping and stress management was a contributing variable. After 1 year there were no significant reductions in recidivism; improvements only became apparent 2 years following the custodial placement. At this point, the authors noted a significant reduction in general recidivism in the Re-ART group compared to the control group $(p<0.001)$, whereby $82.1 \%$ of the control group had reoffended with a general offense compared with $44.4 \%$ of the Re-ART group. In the same time period, there was also significant reduction in violent recidivism for the Re-ART group compared to the control group $(p<0.05)$. After 3 years, both reductions remained significant $(p<0.05)$. The groups did not differ on recidivism regarding property crimes with violence after 1 , 2 or 3 years (Hoogsteder et al. 2018).

The final study to use a pre- and post-test matched group design examined the benefits of a mental health diversion intervention (Haines et al. 2015). This intervention involved targeting children and youth with mental health and/or developmental problems as soon as they entered the youth justice system. Youth practitioners referred participants to one of four Youth Offending Teams engaged in this study. Participants then received improved access to specialized services such as the Child and Adolescent Mental Health Services (CAMHS) and/or referral to other relevant statutory or voluntary agencies. The authors regressed data gathered from the Youth Offending Teams' own database pertaining to "areas of concern and vulnerability" in relation to both mental health and other risk areas against re-offending for the entire sample. Results revealed that the only variable that significantly positively correlated with continued offending was previous offending. However, mental health factors, specifically being unhappy, dissatisfied, and having low self-esteem had a positive relationship with re-offending. Following the mental health diversion intervention, analysis of re-offending data 15-30 months later took place. Despite re-offending rates remaining equal in both intervention and control groups, the intervention group took significantly longer to re-offend than their controls in two of the Youth Offending Teams (580 days vs 334 days and 220 days vs 84 days) (Haines et al. 2015).

\section{Studies Reporting Pre- and Post-psychological Assessment for Intervention Groups Only}

A study assessing the impact of Value-based Therapeutic Environments (VBTE) on re-offending employed a pre- and 
post-test matched group design (Strom et al. 2017). VBTE is a multi-purpose hybrid behavioral model incorporating both value-based and skills-based CBT components via an individualized approach. VBTE teaches participants ten key life skills through a rewards system that includes tolerating feedback, accepting "no" for an answer, asking permission, following instructions, developing conversation and disagreement skills, ignoring inappropriate behavior of others, and respecting and helping others. Program length varied from one month to one year, and the youth received four months of aftercare on their return to the community. In terms of psychological changes, the authors report significant improvements in self-image, goal orientation, honesty, empathy, positive decision-making, and personal development. The largest improvement was in positive decision-making which increased from 4 to $43 \%$. In terms of re-offending, results revealed that the number of days until the first re-offence was significantly greater for the VBTE group (214 days) than the control group (182 days). Further, 57\% of high risk/need youth in the VBTE group re-offended compared to $73 \%$ of high risk/need youth in the control group. The program also reduced the likelihood of a violent re-offence charge by $67 \%$ and any new charge by $49 \%$. In other words, those youth whose risks and needs were greater benefitted more from the program (Strom et al. 2017).

An evaluation of the impact of a "Re-entry" intervention also used a pre- and post-test matched group design with a control and an intervention group to test its impact on reoffending (Bouffard and Bergseth 2008). This intervention involves transitional coordinators (paid mentors) building a relationship with the youth while they are in custody and then continuing this mentoring for 6 months following their release. During this time, the mentor coordinates re-integrative community activities relevant to the young person. In terms of psychological change, there was a significant reduction in risk/need scores of $17 \%$ for the intervention group. However, the study did not state which specific social or psychological risks/needs reduced and as the control group did not receive the same assessment, we cannot say that these changes were due to the intervention. In terms of re-offending, results following the re-entry intervention showed that during the 6 months following release from custody, a statistically significant between group difference occurred where $37 \%$ of the intervention group re-offended compared to $49 \%$ of the control group. However, as there are no re-offending results following the cessation of the mentoring support it is unclear if changes sustained beyond the 6 months (Bouffard and Bergseth 2008).

\section{Studies Reporting Psychological Measures Pre-intervention Only}

A pilot evaluation of "Teen Court", normally utilized with first time offenders, demonstrated success in reducing recidivism with repeat offenders (Forgays and DeMilio 2005). The aim was reintegrating the individual into society through reparation activities, described as being "socially and personally" challenging for the youth, but ultimately empowering (e.g., writing letters of apology). A unique factor in this Teen Court is that following successful completion of their sentence, participants can then become peer judges themselves. Teen Court Jurors may therefore include former youth who have offended. In this study, self-worth profiles assessed prior in the intervention group showed that these youth had low self-acceptance (suggesting they would like to be different from how they were) (Harter 1985). Following their sentencing, a significant and unexpected number of participants chose to continue their involvement as peer jurors. Re-offending results showed that just $12 \%$ of the intervention group had re-offended 6-months later (mostly theft related). In the control group, 38\% re-offended with theft or assault. The authors surmise that low self-worth, coupled with a desire to change, offers a possible psychological explanation for the effectiveness of this Teen Court (Forgays and DeMilio 2005). This led the authors to suggest that the role of personal empowerment may help enable antisocial youth to adopt prosocial values via accessible prosocial opportunities (cf. Mohajer and Earnest 2009).

A further study to employ a matched group design tested the efficacy of Decompression Treatment (DT) on re-offending (Caldwell and Rybroek 2001). This design included two control groups whereby one received standard therapeutic intervention services in the same juvenile center as the intervention group, while the second was based in a conventional correctional facility. DT focuses specifically on reducing defiance and targets the hardest to manage youth who are unresponsive to standard therapeutic intervention. The program developers theorize that punishment increases anti-social behavior and serves to further increase antagonism towards society. Decompression therefore refers to the method of breaking this cycle of aggressive behavior (Caldwell and Rybroek 2001). This in turn should reduce defiance and aggression to the extent that the individual can then access rehabilitative interventions. As well as a behavioral outcome, a reduction in defiance also suggests an improved psychological state in the context of a custodial placement. Re-offending data showed that after 532 days post-intervention, $10 \%$ of the DT intervention group re-offended, $20 \%$ of those receiving standard therapeutic intervention had reoffended, and $70 \%$ of the control group receiving standard correctional rehabilitation had re-offended (Caldwell and Rybroek 2001).

A further evaluation of DT with a larger sample matched intervention and control groups on predictions of re-offending, IQ levels, conduct disorder symptoms and substance abuse (Caldwell et al. 2006). Both groups indicated high probability of re-offending, below average IQ levels, high 
conduct disorder symptoms and extremely high levels of substance abuse. Results 2 years following DT showed that $57 \%$ of the intervention group re-offended in the institution or community compared with $78 \%$ of their controls. This between group difference was significant at the $(p<0.01)$ level. However, following the use of propensity score matching, the intervention showed no impact on general recidivism in the community. Nevertheless, the effects on violent re-offending remained significant (see Table 1). Specifically, 2 years after release, $10 \%$ of the control group accounted for 16 homicides while none of the intervention group received homicide charges (Caldwell et al. 2006). Although both studies draw attention to the relevance of reduced defiance, they did not specify the therapeutic intervention received following DT, nor conduct post-measures, hence it is difficult to pinpoint distinct psychological factors following the intervention that led to the reduction in criminal activity.

A final study to utilize psychological assessment preintervention only also utilized a matched-group design to assess the impact of Trauma Affect Regulation Guide to Education and Training (TARGET) on re-offending (Ford and Hawke 2012). TARGET in youth justice settings follows the assumption that problems causing youth to engage in delinquent behavior are largely a result of unrecognized stress reactions (Andershed et al. 2008). Participants received up to 10 TARGET sessions which included training in self-regulation, trauma processing and strengths-based reintegration. To increase sense of control, awareness and safety, TARGET also includes memory re-examination procedures which aim to decrease rumination (dwelling on past upsets), panic or dissociation. To act as role models, all staff members (including caretakers and administration staff) underwent TARGET training by learning and practicing the techniques along with the youth. In addition, those youth who had completed several sessions can act as peer coaches for new participants. The authors report that reoffending declined significantly following implementation of TARGET, but did not provide specific data. In addition, the study only includes recidivism data for those youth who returned to the community, excluding those who moved to another detention center. After controlling for differences between the groups, results revealed that participating in a single session of TARGET in the first 14 days of detention was associated with 0.53 fewer disciplinary incidents and 69 fewer minutes of disciplinary seclusion (Ford and Hawke 2012).

\section{Studies Measuring Re-offending Only}

The following studies did not use psychological assessment to record pre- or post-intervention changes, but they did implement psychological interventions that showed reduced re-offending.

An evaluation using a matched group design to evaluate two CBT interventions, whereby one group received Enhanced Thinking Skills (ETS) and the other received Reasoning and Rehabilitation (R\&R), showed that only ETS reduced recidivism (Cann et al. 2005). Participants receiving ETS took part in a group-based program for $20 \times 2$-h sessions where they learnt thinking patterns and cognitive skills through impulse control, flexible thinking, values and moral reasoning, interpersonal problem solving, social perspective taking, and critical reasoning. R\&R taught participants to address their emotions using reasoning instead of risky or violent behavior over $36 \times 2$-h sessions. Re-offending results 12 months later showed that there was no significant reduction in re-offending in the group who received $R \& R$ compared to their matched comparisons, even after excluding program dropouts. Of those who completed ETS (i.e., excluding program dropouts), $31.4 \%$ re-offended compared to their controls of whom $35.5 \%$ re-offended (between group effect was significant at the $p<0.05$ level). Conversely, program dropouts across both samples increased their offending by $47 \%$. However, 2 years later the positive effects noted in the ETS group had disappeared leading the authors to conclude that further refresher sessions may be necessary to increase the likelihood of sustained change (Cann et al. 2005).

An initial evaluation of the efficacy of a CBT program called RealVictory, showed that engagement in $6 \times 90 \mathrm{~min}$ cognitive behavioral training sessions followed by daily automated phone calls for a year, reduced subsequent arrests by $51 \%$ (Burraston et al. 2012). In this study, 39 youth received the RealVictory program which included personal support in creating individualized long-term goals. Following this, 28 received cell phones and received a twice daily phone call regarding goal progress for one year. The remaining 11 formed a "class-only" intervention group who did not receive the phone option. The control group contained 31 juveniles who received standard probation intervention (Burraston et al. 2012). A further interpretation of the impact of the phone calls involved dividing those who received phone calls into two groups; "high" (answering over half their phone calls) and "low" (answering less than half of their phone calls). Results showed that after 12 months, those who answered more than half their daily calls had the lowest rearrest rate of 39\%. Those who answered less than half their calls had a re-arrest rate of $80 \%$, a similar rate to the control group receiving standard probation who had a re-arrest rate of $90 \%$. The group who participated in the intervention only (i.e., did not receive a cell phone) had a re-arrest rate of 55\% (Burraston et al. 2014).

A replication of the RealVictory intervention employed an RCD approach with a much larger sample (Bahr et al. 
2015). However, results showed that after 12 months, the group receiving 'RealVictory' plus phone calls did not reduce their re-offending compared to the control group. To determine whether the number of calls answered had any relationship with re-offending, the authors undertook further analysis. This analysis revealed the total number of calls answered by the RealVictory group, although it did not achieve statistical significance in relation to general recidivism, it did significantly reduce felony arrests. Specifically, for every additional 100 calls answered, the likelihood of a felony arrest significantly reduced by (Bahr et al. 2015).

\section{Discussion}

Research has shown that experiencing psychological trauma at a young age can hinder normative adolescent psychological development, leading to low levels of self-concept and emotional regulation (Gibson and Clarbour 2017). These factors have been associated with youth who offend and may be a pre-cursor to delinquent behavior such as avoidant coping (e.g., taking drugs) or aggression (Carr et al. 2001). Hence, the purpose of this article was to systematically review relevant interventions targeting the development of specific psychological characteristics hypothesized to reduce re-offending. A total of 14 studies containing 12 different interventions met the criteria for inclusion. These studies showed that re-offending reduced in interventions that demonstrated significant increases in psychological resources. However, it was not always easy to identify which areas of psychological development were associated with reduced re-offending (e.g., Bahr et al. 2015; Bouffard and Bergseth 2008; Burraston et al. 2014; Caldwell and Rybroek 2001; Caldwell et al. 2006; Cann et al. 2005; Ford and Hawke 2012; Forgays and DeMilio 2005; Haines et al. 2015).

Other studies were much clearer in demonstrating this link. For example, the program "A New Direction" increased sense of coherence (SOC) and reduced criminal thinking styles leading to near total desistance up to 2-years postintervention (Lindblom et al. 2017). A recent systematic review found that youth who were depressed or anxious, misused drugs and alcohol, had poor social skills or conduct problems, or engaged in delinquent behavior were also more likely to have low sense of coherence (Lansimies et al. 2017). Despite SOC developing during adolescence, studies have reported that SOC (and reductions in re-offending) can increase following intervention with adult men (Lindblom et al. 2018). Furthermore, in a study of incarcerated women, increased SOC related to a significant decrease in global emotional distress (Höjdahl et al. 2015). Therefore, SOC appears to have strong grounding for subsequent intervention work in these at-risk populations.
One study reported that increasing the ability to recognize facial expressions (fear and anger) led to reduced severity of re-offending (Hubble et al. 2015). Related research provides further evidence for the benefits of emotion skills training for youth with callous-unemotional (CU) traits (Lui et al. 2019). Specifically, intervention participants significantly increased perspective-taking compared to their controls. Further, the control group reported lower levels of self-reported empathy and pro-social behavior, whereas the intervention group either declined less or had minimal change (Lui et al. 2019). These results reflect those reported in in the results section, whereby emotional skills training appeared to have prevented deteriorating symptoms of CU (Hubble et al. 2015). Programs to augment the emotional development of youth may result in increased likelihood of empathizing with and behaving pro-socially towards others thus decreasing the likelihood of antagonistic behaviors (Lui et al. 2019). Relatedly, the Decompression Treatment intervention also found targeting of defiance plus therapeutic intervention reduced the severity of re-offending (Caldwell et al. 2006).

In contrast to the New Directions intervention, the HIT intervention found certain aspects of criminal thinking such as justification of crime did not reduce (Farrington et al. 2002). However, it did provide further evidence that psychological improvements (e.g., being less anti-staff and having better control of aggression) related to reduced re-offending. In line with strain theory, increased pro-social behaviors may enable youth to achieve goals via agreeable ways such as through pro-social relationships (Boeck et al. 2008). For example, the evaluators of the Re-entry intervention suggest its success may have been due to a specific focus on facilitating community networking (Bouffard and Bergseth 2008). Similar intensive aftercare programs that were not successful in reducing re-offending did not implement the creation of community support networks in any systemic way (Wiebush et al. 2005).

Both the Re-ART and VBTE interventions clearly demonstrated that improvements in negative attitudes, personal development and positive decision making related to a significant reduction in offending. Specifically, Re-ART succeeded in reducing violent and general re-offending across the sample (Hoogsteder et al. 2018). VBTE succeeded in reducing re-offending only in participants with a higher risk of re-offending and reported the largest improvement was in positive decision-making (Strom et al. 2017). ReART's program evaluators suggest its success may be due its responsivity-focused approach, which connects to the adolescent's frame of reference (Hoogsteder et al. 2012, 2018). This approach involves staff seeing the youth's perceptual world as they do, facilitating affinity with their frame of reference (e.g. Bowen et al. 2013a, b). The cultural training 
provided also enabled program staff to include ethnic sensitivity into their approach.

The TARGET intervention, which focused on psychological well-being and included the opportunity for youth to become peer mentors following participation, reduced subsequent disciplinary problems in those participating (Ford and Hawke 2012). A separate study evaluating TARGET in a youth detention center reported both decreased negative affect (e.g., depression, defiance, aggression) and increased positive affect (e.g., optimism) for the intervention group only (Marrow et al. 2012). A further strength of TARGET is that all staff members and those youth who had completed several sessions can act as peer coaches for new participants, thereby increasing the support networks available.

A potential moderating variable applicable to all intervention success is the individual's motivation to engage (Bahr et al. 2015; Burraston et al. 2014; Cann et al. 2005). One way to increase motivation to change is to increase empowerment, via for example perceived power and control (Mohajer and Earnest 2009). The Teen Court reported on in this review offered participants the opportunity to become peer judges following sentence completion, suggesting increased perceptions of empowerment may have led to the higher than expected number of youths taking this opportunity (Forgays and DeMilio 2005). Empowerment is an additional theoretical perspective to those normally cited for Teen Courts (peer/procedural justice, deterrence, labeling, restorative justice, law-related education, and skill building; Butts et al. 2002).

This review has highlighted the importance of matching interventions to individual needs. For example, intensive aftercare programs seem more effective when they include community integration and $R \& R$ has greater success with adults. Likewise, Teen Courts appear more effective with repeat offenders rather than first-time offenders (who normally receive this intervention). A meta-analysis of Teen Court reported non-significant treatment effects, but in looking specifically at those including repeat offenders, effects become significant (Bouchard et al. 2017). This draws attention to the relevance of matching intervention content, style, and intensity to each youth on a case by case basis and may help to explain discrepant findings in intervention studies.

\section{No Consensus in Reporting Recidivism/Little Consideration of Psychological Changes}

Of the studies reviewed, follow-up data regarding reoffending post-intervention varied from 6 to 36 months. Intervention success (re-offences recorded) and the definition of assessment of intervention success also varied from study to study. That is, some recorded the number of re-offences over a set time period (e.g., Farrington et al. 2002). Some reported the number of days before the first re-offence (e.g., Haines et al. 2015). Several researchers implied intervention success by noting reductions in the severity of the re-offence or separated violent from nonviolent re-offending (e.g., Caldwell et al. 2006). All studies except one used official arrests or court data that mostly consisted of police records. However, offence reporting systems may mean inflated intervention success due to the length of time between the actual offence being committed and the criminal charge made (St. James-Roberts et al. 2005). Going forward, it is likely that studies should report intervention success by several outcomes (e.g., time and severity) using both official and self-report.

Fundamentally, no interventions assessed long-term psychological changes post-intervention. In other words, it is difficult to know how long intervention effects lasted. Therefore, it is not possible to ascertain whether re-offending was due to the loss of psychological skills developed, or ineffective intervention designs. Previous studies have argued that using only recidivism to measure success is of limited use, and that identification of factors such as psychological resilience related to desistance may improve both measurement of success, and understanding of desistance (Farrington et al. 2000).

\section{Additional Support Post Intervention Increases Success}

One other potential moderating factor to successful intervention outcome is the inclusion of additional support post-intervention. For example, participants in the VBTE study benefited from four months of aftercare after returning to the community (Strom et al. 2017). The Re-entry intervention utilized paid mentors (Bouffard and Bergseth 2008). Evaluation of RealVictory found that individual telephone calls reinforcing goal setting reduced re-offending (for those motivated to answer) (Bahr et al. 2015; Burraston et al. 2014). In line with strain theory, youth returning to communities where opportunities for crime thrive may require greater support against anti-social influences than those experiencing fewer negative influences (Agnew et al. 2001). Several intervention evaluators noted this issue (Caldwell et al. 2006; Hoogsteder et al. 2018; Strom et al. 2017). Adolescence is a time of exceptional psychological development, and further scaffolding and support via environments that bolster opportunities to thrive may be fundamental to sustained change (National Academies of Sciences, Engineering, \& Medicine 2019). Future studies should therefore conduct follow-up support and psychological assessment, along with re-offending data at 3-6 monthly intervals over a prolonged period ( 3 years is the maximum follow-up period noted in this review). For example, a reassessment of the long-term benefits of the 
HIT intervention 10 years post-intervention found intervention effects in reducing reoffending diminished after 4 years (Jolliffe et al. 2013).

\section{Interventions Successful in Reducing Severity of Re-offending}

This review has also shown that some interventions are successful in reducing the severity of the criminal activity itself. For example, several studies found that while levels of re-offending did not change, violent or serious recidivism reduced significantly following intervention (Bahr et al. 2015; Caldwell et al. 2006; Hubble et al. 2015; Strom et al. 2017). Commentators describe both resilience and desistance as dynamic and cumulative processes involving a series of positive repercussions or chain reactions (e.g., Goldstein and Brooks 2013). Reductions in severity of offence may therefore form the beginning of the desistance process in some populations.

\section{Need for Cultural Tailoring}

With regards to race, findings overall suggest that individual ethnic needs are largely unaddressed. In support of this observation, a 10-year review on evidence-based interventions for ethnic minorities found that very few studies analyzed the effects of cultural tailoring on program engagement, outcomes, and mechanisms of change (Pina et al. 2019). In the present review, only 1 out of the 14 studies discussed the importance of cultural sensitivity and provided training for staff (Hoogsteder et al. 2018). Of the six studies that included race as a variable in their analysis, only two reported on those findings. First, evaluation of the HIT intervention demonstrated it was more successful with non-white youth (predicted re-offending was at $42.7 \%$ while actual reoffending was at 16.7\%) (Farrington et al. 2002). Second, assessment of Re-ART, shows that race did not moderate its success (Hoogsteder et al. 2018).

Therefore, researchers should consider individual ethnic needs in future interventions. This becomes especially important when considering the disproportionate numbers of black youth in the youth justice system. For example, the number of black youths in custody in the UK increased by $6 \%$ from 2018 to 2019 , accounting for $28 \%$ of the total youth custody population (Youth Justice Statistics 2018-2019). In the U.S.A., while $14 \%$ of all youth under 18 are black, $42 \%$ of boys and $35 \%$ of girls are in juvenile facilities are black (Sawyer 2019).

\section{Need for Strong Evaluations of Interventions for Females}

Another important finding was that most participants in the studies reviewed were male. Specifically, out of the studies that reported gender, $93 \%$ were male and just $7 \%$ female, meaning that findings in this review may not generalize to females. Evidence on whether interventions need to be gender specific is mixed. For example, some studies show male and female adolescents have different risks and needs (cf. Vitopoulos et al. 2012). Others find that although male and female youth have differing protective factors related to desistance (e.g., religion and positive school experiences for females but not for males) these differences are not statistically significant (Hartman et al. 2009). Nevertheless, there is a clear need for robust evaluations of interventions aimed at female youth. In the U.K., of the 11,900 first-time entrants into Youth Justice Services in England and Wales 2142 were female (Youth Justice Statistics 2018-2019). In the U.S.A in 2015 , of the 884,900 individuals going through juvenile courts, 244,000 were female (Ehrmann et al. 2019).

\section{Counterproductive "One-Size-Fits-All” Nature of Interventions}

Across the studies identified, intervention length and type of psychological assessments used varied considerably. In other words, most studies are standalone programs with little common ground. It is also clear interventions generally used a "one-size fits-all" approach in that everyone received the same intervention (more or less). Such approaches may be counter-productive for youth who have potentially diverse needs, where some may benefit more from individualized interventions in line with any specific developmental needs. For example, CBT programs (apart from those including post-intervention support) are generally more successful for adults, perhaps because cognitive abilities are generally more developed in this population (Mitchell and Palmer 2004). Youth may benefit more from interventions which include a focus on skills normally developed in adolescence, for example perspective taking and abstract thinking (Blakemore and Choudhury 2006).

\section{Importance of Independent Replication}

A further limitation of the interventions in this review is that program developers evaluate most of the interventions. Specifically, of the fourteen studies identified that successfully reduced re-offending, time to re-offend or violent reoffending, the program developers were heavily involved in nine $(64 \%)$ of these. Of the four evaluated by independent researchers, two reported less significant findings overall (Cann et al. 2005; Haines et al. 2015). Hence, replication 
and reliability of the findings remains uncertain. Independent replication of interventions is vital to assess program reliability (cf. Petrosino and Soydan 2005). Further, through replication and extension, practitioners can modify and tailor those interventions towards different populations with diverse needs. While the performance of an intervention under ideal and controlled circumstances demonstrates its efficacy, "real-world" conditions (i.e., when the study is not a demonstration by its developers) enable assessment of overall effectiveness (cf. Fritz and Cleland 2003).

\section{Conclusion}

This study sought to address the research gap concerning development of psychological resilience via interventions, and its contribution to reduced re-offending. No review has previously attempted to identify contributing psychological changes across different studies. Despite some limitations, findings from the fourteen studies reviewed showed that increasing psychological resources related to reduced re-offending rates, increased time to re-offend, or reduced severity of such offences. Overall, increases in positive affect and coping, and decreases in negative affect and aggression positively related to reduced re-offending. The mechanisms by which these changes take place appear to include cognitive function such as positive self-concept and reduced negative attitudes. These processes may be in turn be instrumental in supporting a successful transition into adulthood. For example, a positive self-identity along with reduced antagonism may enable the attainment of goals legitimately through the cultivation of mutually beneficial pro-social community networks. Going forward, tailoring individualized interventions toward cognitive training, while also focusing on the development of inter-personal skills, opportunities for learning and identification of personal strengths and support systems seems fruitful. Although individualized approaches may be more costly and more time consuming than the one size fits all approaches seen in the current review, the long-term effects may just be transformational.

Acknowledgements We would like to thank Stephen Wood the Service Manager for Youth Justice Service for Gwynedd and Isle of Anglesey (SW) for agreeing to part fund this research project.

Author Contributions SB conceived the idea for the systematic review, supervised the study, guided the analysis of the data and contributed to the writing and editing of the manuscript; RH designed and conducted the study, analyzed the data and drafted the manuscript; RR participated in the design, coordination, and editing of the study; $\mathrm{LH}$ participated in the design and coordination of the study. All authors read and approved the final manuscript.
Funding The author(s) disclosed receipt of the following financial support for the research, authorship, and/or publication of this article: The authors acknowledge financial support from the Knowledge Economy Skills Scholarship (KESS II) and Gwynedd/Isle of Anglesey Youth Justice Services to complete this study.

\section{Compliance with Ethical Standards}

Conflict of interest On behalf of all authors, the corresponding author states that there is no conflict of interest. The collaborating company on this project is the Youth Justice Service for Gwynedd and Isle of Anglesey to which none of the authors have any affiliation or financial connections.

Open Access This article is licensed under a Creative Commons Attribution 4.0 International License, which permits use, sharing, adaptation, distribution and reproduction in any medium or format, as long as you give appropriate credit to the original author(s) and the source, provide a link to the Creative Commons licence, and indicate if changes were made. The images or other third party material in this article are included in the article's Creative Commons licence, unless indicated otherwise in a credit line to the material. If material is not included in the article's Creative Commons licence and your intended use is not permitted by statutory regulation or exceeds the permitted use, you will need to obtain permission directly from the copyright holder. To view a copy of this licence, visit http://creativecommons.org/licenses/by/4.0/.

\section{References}

Agaibi, C. E., \& Wilson, J. P. (2005). Trauma, PTSD, and resilience: A review of the literature. Trauma, Violence, \& Abuse, 6, 195-216. https://doi.org/10.1177/1524838005277438.

Agnew, R. (2001). Building on the foundation of general strain theory: Specifying the types of strain most likely to lead to crime and delinquency. Journal of Research in Crime \& Delinquency, 4, 319-362. https://doi.org/10.1177/0022427801038004001.

Agnew, R., \& White, H. R. (1992). An empirical test of general strain theory. Criminology, 30, 475-500. https://doi. org/10.1111/j.1745-9125.1992.tb01113.x.

Andershed, H., Köhler, D., Eno Louden, J., \& Hinrichs, G. (2008). Does the three-factor model of psychopathy identify a problematic subgroup of young offenders? International Journal of Law and Psychiatry, 31, 189-198. https://doi.org/10.1016/j. ijlp.2008.04.003.

Antonovsky, A. (1991). Halsans mysterium [The mystery of health]. Stockholm: Natur och Kultur.

Armour, C. (2012). Mental health in prison: A trauma perspective on importation and deprivation. International Journal of Criminology and Sociological Theory., 5, 886-894.

Armstrong, S., \& Weaver, E. (2013). Persistent punishment: user views of short prison sentences. Howard Journal of Criminal Justice, $52,285-305$.

Association of Directors of Children's Services Ltd. (2019). ADCS Discussion paper: Serious youth violence and knife crime.https ://adcs.org.uk/assets/documentation/ADCS_Discussion_Paper _on_Serious_Youth_Violence_and_Knife_Crime_FINAL.pdf.

*Bahr, S. J., Cherrington, D. J., \& Erickson, L. D. (2015). An evaluation of the impact of goal setting and cell phone calls on juvenile pe-arrests. International Journal of Offender Therapy and Comparative Criminology, 60, 1816-1835. https://doi. org/10.1177/0306624X15588549. 
Barry, M. (2006). Youth offending in transition: The search for social recognition. Abingdon: Routledge.

Blakemore, S. J., \& Choudhury, S. (2006). Development of the adolescent brain: implications for executive function and social cognition. Journal of Child Psychology and Psychiatry, and Allied Disciplines, 47, 296-312. https://doi.org/10.111 1/j.1469-7610.2006.01611.x.

Boeck, T., Flemming, J., \& Kemshall, H. (2008). Social capital, resilience and desistance: The ability to be a risk navigator. British Journal of Community Justice, 6, 5-21.

Borum, R., Bartel, P., \& Forth, A. (2002). Manual for the Structured Assessment of Violence Risk in Youth (SAVRY). Tampa: University of South Florida.

Bouchard, J., \& Wong, J. S. (2017). A jury of their peers: A metaanalysis of the effects of teen court on criminal recidivism. Journal of Youth and Adolescence, 46(7), 1472-1487. https:// doi.org/10.1007/s10964-017-0667-7.

*Bouffard, J. A. \& Bergseth, K. J. (2008). The impact of re-entry services on juvenile offenders' recidivism. Youth Violence and Juvenile Justice, 6, 295-318. https://doi.org/10.1177/00048 65812469973.

Bowen, K. L., Morgan, J. E., Moore, S. C., \& Van Goozen, S. H. M. (2013a). Young offenders' emotion recognition dysfunction across emotion intensities: Explaining variation using psychopathic traits, conduct disorder and offense severity. Journal of Psychopathologic Behavior Assessment, 36, 60-73.

Bowen, S., Sustar, H., Wolstenholme, D., \& Dearden, A. (2013b). Engaging teenagers productively in service design. International Journal of Child-Computer Interaction, 1, 71-81. https://doi. org/10.1016/j.ijcci.2014.02.001.

*Burraston, B. O., Bahr, S. J., \& Cherrington, D. J. (2014). Reducing juvenile delinquency with automated cell phone calls. International Journal of Offender Therapy and Comparative Criminology, 58, 522-536. https://doi.org/10.1177/0306624X13480947.

Burraston, B. O., Cherrington, D. J., \& Bahr, S. J. (2012). Reducing juvenile recidivism with cognitive training and a cell phone follow-up: An evaluation of the RealVictory Program. International Journal of Offender Therapy and Comparative Criminology, 56, 61-80. https://doi.org/10.1177/0306624X10388635.

Butts, J. A., Buck, J., \& Coggeshall, M. B. (2002). The impact of teen court of young offenders. Washington, D.C: Urban Institute Press.

*Caldwell, M., Skeem, J., Salekin, R., \& Van Rybroek, G. (2006). Treatment response of adolescent offenders with psychopathy features: A 2-year follow-up. Criminal Justice and Behavior, 33, 571-596. https://doi.org/10.1177/0093854806288176.

*Caldwell, M. F., \& Van Rybroek, G. J. (2001). Efficacy of a decompression treatment model in the clinical management of violent juvenile offenders. International Journal of Offender Therapy and Comparative Criminology, 45, 469-477. https://doi. org/10.1177/0306624X01454006.

*Cann, J., Falshaw, L., \& Friendship, C. (2005). Understanding 'what works': Accredited cognitive skills programmes for young offenders. Youth Justice, 5, 165-179. https://doi. org/10.1177/147322540500500303.

Carr, M. B., Vandiver, T. A., \& Trish, A. (2001). Risk and protective factors among youth offenders. Adolescence, 36, 409-426.

Committee on Child Maltreatment Research, Policy, and Practice for the Next Decade: Phase II; Board on Children, Youth, and Families; Committee on Law and Justice; Institute of Medicine; National Research Council; Petersen, A. C., Joseph, J., \& Feit, M. (Eds.). (2014). New directions in child abuse and neglect research. Washington, DC: National Academies Press.

Daykin, N., de Viggiani, N., Moriarty, Y., \& Pilkington, P. (2017). Music-making for health and wellbeing in youth justice settings: mediated affordances and the impact of context and social relations. Sociology of Health and Illness, 39, 941-958. https:// doi.org/10.1111/1467-9566.12549.

Diaz, R. (2005). Young people and homelessness. https://england.shelt er.org.uk/_data/assets/pdf_file/0009/48627/Factsheet_Young _People_and_Homelessness_Nov_2005.pdf.

Eichhorn, S., Brähler, E., Franz, M., Friedrich, M., \& Glaesmer, H. (2014). Traumatic experiences, alexithymia, and posttraumatic symptomatology: A cross-sectional population-based study in Germany. European Journal of Psychotraumatology. https://doi. org/10.3402/ejpt.v5.23870.

Ehrmann, S., Hyland, N., \& Puzzanchera, C. (2019, April). Girls in the juvenile justice system. U.S. Department of Justice: Juvenile Justice Statistics. https://ojjdp.ojp.gov/sites/g/files/xyckuh176/ files/pubs/251486.pdf.

Eriksson, M. (2016). The sense of coherence in the salutogenic model of health. In M. B. Mittelmark, S. Sagy, M. Eriksson, et al. (Eds.), The handbook of salutogenesis. Cham: Springer. https:// doi.org/10.1007/978-3-319-04600-6_11.

Evans-Chase, M., \& Zhou, H. (2014). A systematic review of the juvenile justice intervention literature: What it can (and cannot) tell us about what works with delinquent youth. Crime \& Delinquency, 60, 451-470. https://doi.org/10.1177/0011128712 466931.

Fact Sheet on Juvenile Justice. (2008). United Nations Department of Economic and Social Affairs: Youth. www.un.org/development/ desa/youth/juvenile-justice-factsheet.html.

Farrington, D. P. (2000). Explaining and preventing crime: The globalization of knowledge-The American Society of Criminology 1999 presidential address. Criminology, 38, 1-24. https://doi. org/10.1111/j.1745-9125.2000.tb00881.x.

*Farrington, D. P., Ditchfield, J., Hancock, G., Howard, P., Jolliffe, D., Livingston, M. S., \& Painter, K. A. (2002, April). Evaluation of two intensive regimes for young offenders. Home Office. https://www.surrey.ac.uk/law/staff-profiles/documents/homeo fficeyoungoffender.pdf.

Fletcher, D., \& Scott, M. (2010). Psychological stress in sports coaches: A review of 16 concepts, theory and research. Journal of Sports Sciences, 28, 127-137. https://doi.org/10.1080/02640 410903406208.

Ford, J. D., Chapman, J. F., Pearson, G., Borum, R., Hawke, J., \& Wolpaw, J. M. (2008). MAYSI-2 factor structure, reliability, and predictive validity in juvenile detention. Journal of Psychopathology \& Behavioral Assessment, 30, 87-99.

*Ford, J. D., \& Hawke, J. (2012). Trauma affect regulation psychoeducation group and milieu intervention outcomes in juvenile detention facilities. Journal of Aggression, Maltreatment \& Trauma, 21, 365-384. https://doi.org/10.1080/10926 771.2012 .673538 .

*Forgays, D. K., \& DeMilio, L. (2005). Is Teen Court effective for repeat offenders? A test of the restorative justice approach. International Journal of Offender Therapy \& Comparative Criminology, 49, 107-118. https://doi.org/10.1177/0306624X04269411.

Forth, A. E., Kosson, D., \& Hare, R. D. (2003). Psychopathy ChecklistYouth Version. Toronto, ON: Multi-Health Systems.

Fritz, J. M., \& Cleland, J. (2003). Effectiveness versus efficacy: More than a debate over language. The Journal of Arthopaedic and Sports Physical Therapy, 33, 163-165. https://doi.org/10.2519/ jospt.2003.33.4.163.

Gibson, R. A., \& Clarbour, J. (2017). Factorial structure of the Resiliency Scale for Children and Adolescents (RSCA) among incarcerated male adolescent offenders. Journal of Forensic Practice, 19, 23-36. https://doi.org/10.1108/JFP-08-2015-0043.

Global Youth Justice. (2018, March 19). Top 25 crimes, offences and violations. (2018). Global Youth Justice. https://www.globalyout hjustice.org/resources/top-25-crimes/. 
Goldstein, S., \& Brooks, R. B. (Eds.). (2013). Resilience in children (2nd ed.). New York: Springer.

*Haines, A., Lane, S., McGuire, J., Perkins, E., \& Whittington, R. (2015). Offending outcomes of a mental health youth diversion pilot scheme in England. Criminal Behaviour \& Mental Health, 25, 126-140. https://doi.org/10.1002/cbm.1916.s.

Harter, S. (1985). Manual for the self-perception profile for adolescents. Denver: University of Denver Press.

Hartman, J. L., Turner, M. G., Daigle, L. E., Exum, M. L., \& Cullen, F. T. (2009). Exploring the gender differences in protective factors: Implications for understanding resiliency. International Journal of Offender Therapy and Comparative Criminology, 53, 249-277. https://doi.org/10.1177/0306624X08326910.

Hatcher, R. M., McGuire, J., Bilby, C. A. L., Palmer, E. J., \& Hollin, C. R. (2012). Methodological considerations in the evaluation of offender interventions: The problem of attrition. International Journal of Offender Therapy \& Comparative Criminology, 56, 447-464. https://doi.org/10.1177/0306624X11403271.

Höjdahl, T., Magnus, J. H., Mdala, I., Hagen, R., \& Langeland, E. (2015). Emotional distress and sense of coherence in women completing a motivational program in five countries. A prospective study. International Journal of Prisoner Health, 11, 169182. https://doi.org/10.1108/IJPH-10-2014-0037.

Hoogsteder, L. M., Hendriks, J., Van Horn, J., \& Wissink, I. (2012). Responsive aggression regulation therapy: An evaluation study in a juvenile justice institution. Orthopedagogiek: Onderzoek En Praktijk, 51, 481-493.

*Hoogsteder, L. M., Stams, G. J. J. M., Schippers, E. E., \& Bonnes, D. (2018). Responsive aggression regulation therapy (ReART): An evaluation study in a Dutch juvenile justice institution in terms of recidivism. International Journal of Offender Therapy \& Comparative Criminology, 62, 4403-4424. https:// doi.org/10.1177/0306624X18761267.

*Hubble, K., Bowen, K. L., Moore, S. C., \& Van Goozen, S. H. M. (2015). Improving negative emotion recognition in young offenders reduces subsequent crime. PLOS ONE, 10, 1-13. https://doi.org/10.1371/journal.pone.0132035.

Infurna, F. J., Rivers, C. T., Reich, J., \& Zautra, A. J. (2015). Childhood trauma and personal mastery: Their influence on emotional reactivity to everyday events in a community sample of middle-aged adults. PLOS ONE, 10, e0121840. https://doi. org/10.1371/journal.pone.0121840.

Johns, D., Williams, K. S., \& Haines, K. (2018). A study of prolific offending by young people in Wales, 2009-2015. Wales: Welsh Centre for Crime and Social Justice.

Jolliffe, D., Farrington, D. P., \& Howard, P. (2013). How long did it last? A 10-year reconviction follow-up study of high intensity training for young offenders. Journal of Experimental Criminology, 9, 515-531. https://doi.org/10.1007/s1129 2-013-9191-2.

Lansimies, H., Pietila, A., \& Husu, S. H. (2017). A systematic review of adolescents' sense of coherence and health. Scandinavian Journal of Caring Sciences, 31, 651-661. https://doi.org/10.1111/ scs. 12402 .

*Lindblom, S., Eriksson, L., \& Hiltunen, A. J. (2017). Evaluation of the cognitive intervention programme "A New Direction" targeting young offenders in Sweden. Journal of Scandinavian Studies in Criminology \& Crime Prevention, 18, 176-190. https://doi. org/10.1080/14043858.2017.1307545.

Lindblom, S., Eriksson, L., \& Hiltunen, A. J. (2018). Criminality, thinking patterns and treatment effects-evaluation of the Swedish cognitive intervention programme 'new challenges' targeting adult men with a criminal lifestyle. Journal of Scandinavian Studies in Criminology \& Crime Prevention, 19, 204-224. https ://doi.org/10.1080/14043858.2018.1513202.
Lipsey, M. W. (2009). The primary factors that characterize effective interventions with juvenile offenders: A meta-analytic overview. Victims \& Offenders, 4, 124-147. https://doi.org/10.1080/15564 880802612573.

Lui, J. H. L., Barry, C. T., \& Marcus, D. K. (2019). A short-term intervention for adolescents with callous-unemotional traits and emotion-processing deficits. Journal of Social \& Clinical Psychology, 38, 475-500. https://doi.org/10.1521/jscp.2019.38.6.475.

Luthar, S. S., Cicchetti, D., \& Becker, B. (2000). The construct of resilience: A critical evaluation and guidelines for future work. Child development, 71, 543-562. https://doi.org/10.1111/14678624.00164.

Mallet, C. A., \& Tedor, N. K. (2018). Juvenile delinquency: Pathways and prevention. Thousand Oaks, CA: Sage.

Marrow, M. T., Knudsen, K. J., Olafson, E., \& Bucher, S. E. (2012). The value of implementing TARGET within a trauma-informed juvenile justice setting. Journal of Child \& Adolescent Trauma, 5, 257-270. https://doi.org/10.1080/19361521.2012.697105.

McGuire, J. (2008). A review of effective interventions for reducing aggression and violence. Philosophical Transactions of the Royal Society of London B: Biological Sciences, 363, 2577-2597. https ://doi.org/10.1098/rstb.2008.0035.

Ministry of Justice and Youth Justice Board. (2016). Youth custody report: September 2016.https://www.gov.uk/government/stati stics/youth-custody-data.

Mitchell, J., \& Palmer, E. J. (2004). Evaluating the "Reasoning and Rehabilitation" program for young offenders. Journal of Offender Rehabilitation, 39, 31-45. https://doi.org/10.1300/ J076v39n04_03.

Moffitt, T. E. (2003). Life-course-persistent and adolescence-limited antisocial behavior: A 10-year research review and a research agenda. In B. B. Lahey, T. E. Moffitt, \& A. Caspi (Eds.), Causes of conduct disorder and juvenile delinquency (pp. 49-75). New York: The Guilford Press.

Mohajer, N., \& Earnest, J. (2009). Youth empowerment for the most vulnerable: A model based on the pedagogy of Freire and experiences in the field. Health Education, 109, 424-438. https://doi. org/10.1108/09654280910984834.

Moher, D., Liberati, A., Tetzlaff, J., Altman, D. G., Altman, D., Antes, G., et al. (2009). Preferred reporting items for systematic reviews and meta-analyses: The PRISMA statement. PLoS Medicine. https://doi.org/10.1371/journal.pmed.1000097.

Möller, C., Falkenström, F., Larsson, M. H., \& Holmqvist, R. (2014). Mentalizing in young offenders. Psychoanalytic Psychology, 31, 84-99. https://doi.org/10.1037/a0035555.

MST Services (2018, November 1). Do we know the full extent of juvenile recidivism? [Blog post]. https://info.mstservices.com/blog/ juvenile-recidivism-rates.

Mukherjee, S., \& Kumar, U. (2017). Psychological resilience: A conceptual review of theory and research. In U. Kumar (Ed.), The Routledge international handbook of psychosocial resilience. New York: Routledge.

National Academies of Sciences, Engineering, and Medicine (2019). The promise of adolescence: Realizing opportunity for all youth. Washington, DC: The National Academies Press. $10.17226 / 25388$

Petrosino, A., \& Soydan, H. (2005). The impact of program developers as evaluators on criminal recidivism: Results from meta-analyses of experimental and quasi-experimental research. Journal of Experimental Criminology, 1, 435-450.

Pina, A. A., Polo, A. J., \& Huey, S. J. (2019). Evidence-based psychosocial interventions for ethnic minority youth: The 10-Year Update. Journal of Clinical Child \& Adolescent Psychology, 48, 179-202. https://doi.org/10.1080/15374416.2019.1567350. 
Roger, D., \& Masters, R. (1997). The development and evaluation of an emotion control training programme for sex offenders. Legal \& Criminological Psychology, 2, 51-64.

Roger, D., \& Najarian, B. (1989). The construction and validation of a new scale for measuring emotion control. Personality \& Individual Differences, $8,845-853$.

Rutter, M. (2006). Implications of resilience concepts for scientific understanding. Annals of the New York Academy of Sciences, 1094, 1-12. https://doi.org/10.1196/annals.1376.002.

Salekin, R. T. (2015). Forensic evaluation and treatment of juveniles: Innovation and best practice. Washington, DC: American Psychological Association.

Sawyer, W. (2019). Youth Confinement: The Whole Pie 2019. Prison Policy Initiative. https://www.prisonpolicy.org/reports/youth2019.html.

Serious Crime Act, Chapter 1. (2007). https://www.legislation.gov.uk/ ukpga/2007/27/contents.

Shields, I. W., \& Simourd, D. (1991). Predicting predatory behavior in a population of incarcerated young offenders. Criminal Justice \& Behavior, 18, 180-194.

Sirriyeh, R., Lawton, R., Gardner, P., \& Armitage, G. (2012). Reviewing studies with diverse designs: The development and evaluation of a new tool. Journal of Evaluation in Clinical Practice, 18, 746-752. https://doi.org/10.1111/j.1365-2753.2011.01662.x.

Snow, P. C., Woodward, M., Mathis, M., \& Powell, M. B. (2015). Language functioning, mental health and alexithymia in incarcerated young offenders. International Journal of SpeechLanguage Pathology, 18, 20-31. https://doi.org/10.3109/17549 507.2015.1081291.

St. James-Roberts, I., Greenlaw, G., Simon, A., \& Hurry, J. (2005). National Evaluation of Youth Justice Board Mentoring Schemes 2001 to 2004. London: Youth Justice Board.

Steinberg, L., Chung, H. L., \& Little, M. (2004). Re-entry of young offender from the justice system: A developmental perspective. Youth violence and juvenile justice, 2, 21. https://doi. org/10.1177/1541204003260045.

Stoddard, S. A., Whiteside, L., Zimmerman, M. A., Cunningham, R. M., Chermack, S. T., \& Walton, M. A. (2013). The relationship between cumulative risk and promotive factors and violent behavior among urban adolescents. American Journal of Community Psychology, 51, 57-65. https://doi.org/10.1007/s10464-012-9541-7.

*Strom, K. J., Hendrix, J. A., Dawes, D., \& Anderson, S. H. (2017). An outcome evaluation of the Methodist Home for Children's value-based therapeutic environment model. Journal of Experimental Criminology, 13, 101-124. https://doi.org/10.1007/s1129 2-016-9275-x.

Thornton, D. (1987). Assessing custodial adjustment. In B. J. McGurk, D. M. Thornton, \& M. Williams (Eds.), Applying psychology to imprisonment (pp. 445-462). London: HMSO.

Trundle, G., \& Hutchinson, R. (2020). The phased model of adventure therapy: trauma-focussed, low arousal, \& positive behavioural support. Journal of Adventure Education \& Outdoor Learning. https://doi.org/10.1080/14729679.2020.1736109.

Turner, T. (2015). Legal writing from the ground up: Process, principles, and possibilities. Alphen aan den Rijn: Wolters Kluwer.

U. S. Department of Justice. (2015). About violent gangs. https://www. justice.gov/criminal-ocgs/about-violent-gangs.

Vitopoulos, N. A., Peterson-Badali, M., \& Skilling, T. A. (2012). The relationship between matching service to criminogenic need and recidivism in male and female youth: Examining the RNR principles in practice. Criminal Justice \& Behavior, 39, 1025-1041. https://doi.org/10.1177/0093854812442895.

Walters, G. D. (1995a). The psychological inventory of criminal thinking styles, part I. Reliability and preliminary validity. Criminal Justice \& Behaviour, 22, 307-325.

Walters, G. D. (1995b). The psychological inventory of criminal thinking styles, part II. Identifying simulated response sets. Criminal Justice \& Behaviour, 22, 437-445.

Walters, G. D. (1996). The psychological inventory of criminal thinking styles, part III. Predictive validity. International Journal of Offender Therapy \& Comparative Criminology, 40, 105-112.

Walters, G. D. (2002). The psychological inventory of criminal thinking styles (PICTS). Assessment, 9, 278-291. https://doi. org/10.1177/1073191102009003007.

Wiebush, R. G., Wagner, D., McNulty, B., Wang, Y., \& Le, T. (2005). Implementation and outcome evaluation of the intensive aftercare program: Final report. Washington, DC: National Council on Crime and Delinquency.

Wilson, H. A., \& Hoge, R. D. (2013). The effect of youth diversion programs on recidivism: A meta-analytic review. Criminal Justice \& Behavior, 40, 497-518. https://doi.org/10.1177/0093854812451089.

Wolff, K. T., \& Baglivio, M. T. (2017). Adverse childhood experiences, negative emotionality, and pathways to juvenile recidivism. Crime \& Delinquency, 63, 1495-1521. https://doi. org/10.1177/0011128715627469.

Wood, D., Crapnell, T., Lau, L., Bennett, A., Lotstein, D., Ferris, M., et al. (2018). Emerging adulthood as a critical stage in the life course. In N. Halfon, C. B. Forrest, R. M. Lerner, \& E. M. Faustman (Eds.), Handbook of life course health development (pp. 123-143). Cham: Springer.

Youth Justice Board for England and Wales. (2018). Youth Justice Board for England and Wales-Strategic Plan 2018-21 (pp. 1-13). https://www.gov.uk/government/publications/youth-justi ce-board-for-england-and-wales-strategic-plan-2018-21.

Youth Justice Statistics. (2018-2019). Youth Justice Legal Center, February 2020. https://yjlc.uk/youth-justice-statistics-2018-2019/.

Youth justice facts and figures. (2020). Beyond Youth Custody. https:// www.beyondyouthcustody.net/about/facts-and-stats/.

Publisher's Note Springer Nature remains neutral with regard to jurisdictional claims in published maps and institutional affiliations.

\section{Affiliations}

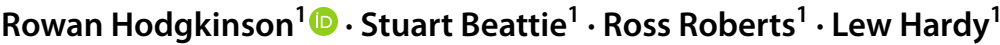

Stuart Beattie

S.J.Beattie@bangor.ac.uk

Ross Roberts

ross.roberts@bangor.ac.uk

Lew Hardy

lewhardy19@gmail.com
1 Institute for the Psychology of Elite Performance, School of Sports, Health and Exercise Science, Bangor University, The George Building, Holyhead Rd., Bangor, Gwynedd LL57 2PZ, UK 